\title{
Part 3: Consumption and Investment
}

\section{Chapters}

II Consumption

12 Consumption under Uncertainty and Macro Finance ......................................................... 171

13 Investment ................................................................................................................................ 189

LSE

ADVANCED MACROECONOMICS aneasy guride
Filipe Campante, Federico Sturzenegger and Andrés Velasco

Advanced Macroeconomics

LSE Press

Suggested citation: Campante, Filipe; Sturzenegger, Federico; and Velasco, Andrés. (2021) 'Part 3: Consumption and Investment', in Filipe Campante, Federico Sturzenegger and Andrés Velasco, Advanced Macro-Economics: An Easy Guide. London: LSE Press, 2021. Chapters 11-13. https://doi.org/10.31389//sepress.ame.3 


\section{Consumption and Investment}





\section{Consumption}

The usefulness of the tools that we have studied so far in the book goes well beyond the issue of economic growth and capital accumulation that has kept us busy so far. In fact, those tools enable us to think about all kinds of dynamic issues, in macroeconomics and beyond. As we will see, the same tradeoffs arise again and again: how do individuals trade off today vs tomorrow? It depends on the rate of return, on impatience, and on the willingness to shift consumption over time, all things that are captured by our old friend, the Euler equation! What are the constraints that the market imposes on individual behaviour? You won't be able to borrow if you are doing something unsustainable. Well, it's the no-Ponzi game condition! How should we deal with shocks, foreseen and unforeseen? This leads to lending and borrowing and, at an aggregate level, the current account!

All of these issues are raised when we deal with some of the most important (and inherently dynamic) issues in macroeconomics: the determinants of consumption and investment, fiscal policy, and monetary policy. To these issues we will now turn.

We start by looking at one of the most important macroeconomic aggregates, namely consumption. In order to understand consumption, we will go back to the basics of individual optimisation and the intertemporal choice of how much to save and consume. Our investigation into the determinants of consumption will proceed in two steps. First, we will analyse the consumer's choice in a context of full certainty. We will be careful with the algebra, so readers who feel comfortable with the solutions can skip the detail, while others may find the careful step-by-step procedure useful. Then, in the next chapter, we will add the realistic trait of uncertainty (however simply it is modelled). In the process, we will also see some important connections between macroeconomics and finance.

\section{1 | Consumption without uncertainty}

The main result of the consumption theory without uncertainty is that of consumption smoothing. People try to achieve as smooth a consumption profile as possible, by choosing a consumption level that is consistent with their intertemporal resources and saving and borrowing along the way to smooth the volatility in income paths.

Let's start with the case where there is one representative consumer living in a closed economy, and no population growth. All quantities (in small-case letters) are per-capita. The typical consumer-worker provides one unit of labour inelastically. Their problem is how much to save and how much to consume

\section{How to cite this book chapter:}

Campante, F., Sturzenegger, F. and Velasco, A. 2021. Advanced Macroeconomics: An Easy Guide.

Ch. 11. 'Consumption', pp. 161-170. London: LSE Press. DOI: https://doi.org/10.31389/lsepress.ame.k License: CC-BY-NC 4.0. 
over their lifetime of length $T$. This (unlike in the analysis of intertemporal choice that we pursued in the context of the Neoclassical Growth Model) will be partial equilibrium analysis: we take the interest rate $r$ and the wage rate $w$ as exogenous.

\subsection{1 | The consumer's problem}

This will be formally very similar to what we have encountered before. The utility function is

$$
\int_{0}^{T} u\left(c_{t}\right) e^{-\rho t} d t
$$

where $c_{t}$ denotes consumption and $\rho(>0)$ is the rate of time preference. Assume $u^{\prime}\left(c_{t}\right)>0, u^{\prime \prime}\left(c_{t}\right) \leq 0$, and that Inada conditions are satisfied.

The resource constraint is

$$
\dot{b}_{t}=r b_{t}+w_{t}-c_{t},
$$

where $w_{t}$ is the real wage and $b_{t}$ is the stock of bonds the agent owns. Let us assume that the real interest rate $r$ is equal to $\rho .^{1}$

The agent is also constrained by the no-Ponzi game (NPG) or solvency condition:

$$
b_{T} e^{-r T} \geq 0
$$

\section{Solution to consumer's problem}

The consumer maximises (11.1) subject to (11.2) and (11.3) for given and $b_{0}$. The current value Hamiltonian for the problem can be written as

$$
H=u\left(c_{t}\right)+\lambda_{t}\left[r b_{t}+w_{t}-c_{t}\right] .
$$

Note that $c$ is a control variable (jumpy), $b$ is the state variable (sticky), and $\lambda$ is the costate variable (the multiplier associated with the intertemporal budget constraint, also jumpy). The costate has an intuitive interpretation: the marginal value as of time $t$ of an additional unit of the state (assets $b$, in this case).

The optimality conditions are

$$
\begin{gathered}
u^{\prime}\left(c_{t}\right)=\lambda_{t}, \\
\frac{\dot{\lambda}_{t}}{\lambda_{t}}=\rho-r, \\
\lambda_{T} b_{T} e^{-\rho T}=0 .
\end{gathered}
$$

This last expression is the transversality condition (TVC).

\subsection{2 | Solving for the time profile and level of consumption}

Take (11.5) and differentiate both sides with respect to time

$$
u^{\prime \prime}\left(c_{t}\right) \dot{c}_{t}=\dot{\lambda}_{t}
$$


Divide this by (11.5) and rearrange

$$
\frac{u^{\prime \prime}\left(c_{t}\right) c_{t}}{u^{\prime}\left(c_{t}\right)} \frac{\dot{c}_{t}}{c_{t}}=\frac{\dot{\lambda}_{t}}{\lambda_{t}}
$$

Now, as we've seen before, define

$$
\sigma \equiv\left[-\frac{u^{\prime \prime}\left(c_{t}\right) c_{t}}{u^{\prime}\left(c_{t}\right)}\right]^{-1}>0
$$

as the elasticity of intertemporal substitution in consumption. Then, (11.9) becomes

$$
\frac{\dot{c}_{t}}{c_{t}}=-\sigma \frac{\dot{\lambda}_{t}}{\lambda_{t}} .
$$

Finally using (11.6) in (11.11) we obtain (what a surprise!):

$$
\frac{\dot{c}_{t}}{c_{t}}=\sigma(r-\rho)=0 .
$$

Equation (11.12) says that consumption is constant since we assume $r=\rho$. It follows then that

$$
c_{t}=c^{*}
$$

so that consumption is constant.

We now need to solve for the level of consumption $c^{*}$. Using (11.13) in (11.2) we get

$$
\dot{b}_{t}=r b_{t}+w_{t}-c^{*},
$$

which is a differential equation in $b$, whose solution is, for any time $t>0$,

$$
b_{t}=\int_{0}^{t} w_{s} e^{r(t-v)} d s-\left(e^{r t}-1\right) \frac{c^{*}}{r}+b_{0} e^{r t} .
$$

where time $v$ is any moment between 0 and $t$. Evaluating this at $t=T$ (the terminal period) we obtain the stock of bonds at the end of the agent's life:

$$
b_{T}=\int_{0}^{T} w_{s} e^{r(T-s)} d s-\left(e^{r T}-1\right) \frac{c^{*}}{r}+b_{0} e^{r T} .
$$

Dividing both sides by $e^{r T}$ and rearranging, we have

$$
b_{T} e^{-r T}=\int_{0}^{T} w_{t} e^{-r s} d s-\left(1-e^{-r T}\right) \frac{c^{*}}{r}+b_{0} .
$$

Notice that using (11.5), (11.7), and (11.13), the TVC can be written as

$$
u^{\prime}\left(c^{*}\right) b_{T} e^{-r T}=0 .
$$

Since clearly $u^{\prime}\left(c^{*}\right) \neq 0$ (this would require $c^{*} \rightarrow \infty$ ), for the TVC to hold it must be the case that $b_{T} e^{-r T}=0$. Applying this to (11.17) and rearranging we have

$$
\frac{c^{*}}{r}\left(1-e^{-r T}\right)=b_{0}+\int_{0}^{T} w_{s} e^{-r s} d s .
$$

The LHS of this equation is the net present value (NPV) of consumption as of time 0 , and the RHS the NPV of resources as of time 0 . 


\subsection{The permanent income hypothesis}

Dividing (11.19) through by $\left(1-e^{-r T}\right)$ and multiplying through by $r$ we have

$$
c^{*}=\frac{r b_{0}+r \int_{0}^{T} w_{t} e^{-r t} d t}{1-e^{-r T}} .
$$

The RHS of this expression can be thought of as the permanent income of the agent as of time 0 . That is what they optimally consume.

What is savings in this case? Define

$$
\begin{aligned}
s_{t} & =w_{t}+r b_{t}-c_{t} \\
& =r\left(b_{t}-\frac{b_{0}}{1-e^{-r T}}\right)+\left(w_{t}-\frac{r \int_{0}^{T} w_{t} e^{-r t} d t}{1-e^{-r T}}\right) .
\end{aligned}
$$

Hence, savings is high when a) bond-holdings are high relative to their permanent level, and b) current wage income is high relative to its permanent level. Conversely, when current income is less than permanent income, saving can be negative. Thus, the individual uses saving and borrowing to smooth the path of consumption. (Where have we seen that before?)

This is the key idea of Friedman (1957). Before then, economists used to think of a rule of thumb in which consumption would be a linear function of current disposable income. But if you think about it, from introspection, is this really the case? It turns out that the data also belied that vision, and Friedman (1957) gave an explanation for that.

\subsection{1 | The case of constant labour income}

Note also that if $w_{t}=w$, the expression for consumption becomes

$$
c^{*}=\frac{r b_{0}+r w \int_{0}^{T} e^{-r t} d t}{1-e^{-r T}}=\frac{r b_{0}}{1-e^{-r T}}+w .
$$

Moreover, if $T \rightarrow \infty$, this becomes

$$
c^{*}=r b_{0}+w
$$

which has a clear interpretation: $r b_{0}+w$ is what the agent can consume on a permanent (constant) basis forever.

What is the path of bond-holdings over time? Continue considering the case in which $w$ is constant, but $T$ remains finite. In that case the equation for bonds (11.15) becomes

$$
b_{t}=\left(e^{r t}-1\right) \frac{w-c^{*}}{r}+b_{0} e^{r t}
$$

Using (11.22) in here we get

$$
b_{t}=\left(\frac{1-e^{-r(T-t)}}{1-e^{-r T}}\right) b_{0}<b_{0}
$$

Notice that

$$
\frac{d b_{t}}{d t}=-r\left(\frac{e^{-r(T-t)}}{1-e^{-r T}}\right) b_{0}<0
$$


Figure 11.1 Bondholdings with constant income

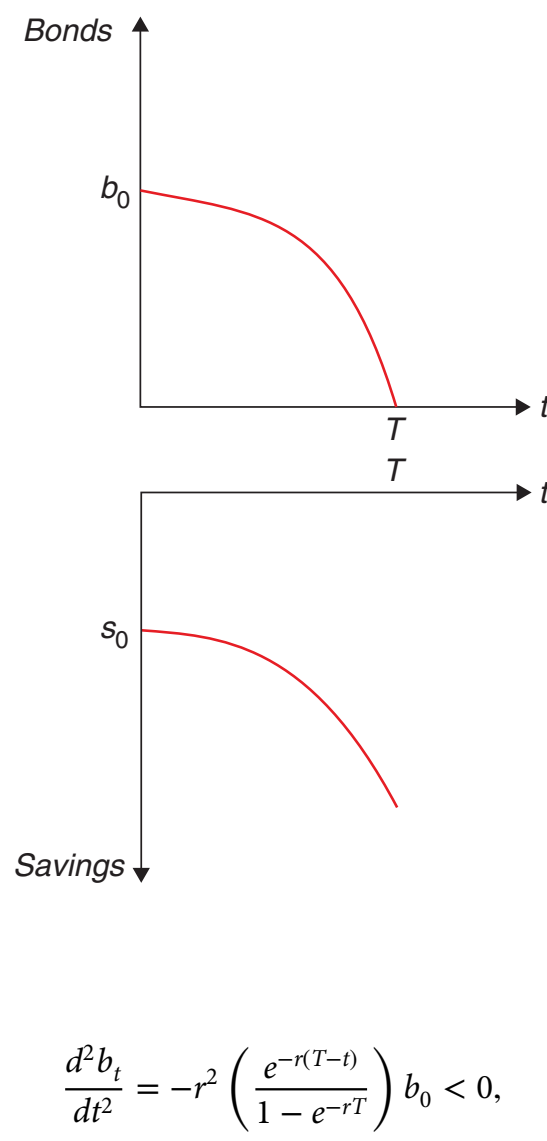

so that bond-holdings decline, and at an accelerating rate, until they are exhausted at time $T$. Figure 11.1 shows this path.

\subsection{2 | The effects of non-constant labour income}

Suppose now that wages have the following path:

$$
w_{t}=\left\{\begin{array}{l}
w^{H}, 0 \leq t<T^{\prime} \\
w^{L}, T^{\prime} \leq t<T
\end{array}, T^{\prime}<T, w^{H}>w^{L} .\right.
$$

Then, we can use (11.20) to figure out what constant consumption is:

$$
\begin{aligned}
c^{*} & =\frac{r b_{0}+w^{H} r \int_{0}^{T^{\prime}} e^{-r t} d t+w^{L} r \int_{T^{\prime}}^{T} e^{-r t} d t}{1-e^{-r T}} \\
& =\frac{r b_{0}+w^{H}\left(1-e^{-r T^{\prime}}\right)+w^{L}\left(e^{-r T^{\prime}}-e^{-r T}\right)}{1-e^{-r T}} .
\end{aligned}
$$


For $t<T^{\prime}$, saving is given by

$$
\begin{aligned}
s_{t} & =w^{H}+r b_{t}-c_{t} \\
& =r\left(b_{t}-\frac{b_{0}}{1-e^{-r T}}\right)+\left(w^{H}-\frac{w^{H}\left(1-e^{-r T^{\prime}}\right)+w^{L}\left(e^{-r T^{\prime}}-e^{-r T}\right)}{1-e^{-r T}}\right) .
\end{aligned}
$$

What are bond-holdings along this path? In this case the equation for bonds (11.15) becomes, for $t<T^{\prime}$

$$
b_{t}=b_{0} \frac{1-e^{-r(T-t)}}{1-e^{-r T}}+\left(e^{r t}-1\right) \frac{w^{H}-w^{L}}{r}\left(\frac{e^{-r T^{\prime}}-e^{-r T}}{1-e^{-r T}}\right)
$$

Notice

$$
\begin{aligned}
\frac{d b_{t}}{d t} & =\left\{-r b_{0} \frac{e^{-r T}}{1-e^{-r T}}+\left(w^{H}-w^{L}\right)\left(\frac{e^{-r T^{\prime}}-e^{-r T}}{1-e^{-r T}}\right)\right\} e^{r t} \\
\frac{d^{2} b_{t}}{d t^{2}} & =\left\{-r b_{0} \frac{e^{-r T}}{1-e^{-r T}}+\left(w^{H}-w^{L}\right)\left(\frac{e^{-r T^{\prime}}-e^{-r T}}{1-e^{-r T}}\right)\right\} r e^{r t}
\end{aligned}
$$

so that bond-holdings are increasing at an increasing rate for $t<T^{\prime}$ if $b_{0}$ is sufficiently small.

Plugging this into (11.31) we obtain

$$
\begin{aligned}
s_{t}= & -\left(\frac{e^{-r(T-t)}}{1-e^{-r T}}\right) r b_{0}+w^{H} \\
& -w^{H}\left[1-e^{r t}\left(\frac{e^{-r T^{\prime}}-e^{-r T}}{1-e^{-r T}}\right)\right]-w^{L} e^{r t}\left(\frac{e^{-r T^{\prime}}-e^{-r T}}{1-e^{-r T}}\right)
\end{aligned}
$$

so that, yet again savings is high when current wage income is above permanent wage income.

Simplifying, this last expression becomes

$$
s_{t}=\left\{-r b_{0} \frac{e^{-r T}}{1-e^{-r T}}+\left(w^{H}-w^{L}\right)\left(\frac{e^{-r T^{\prime}}-e^{-r T}}{1-e^{-r T}}\right)\right\} e^{r t} .
$$

Notice

$$
\begin{gathered}
\frac{d s_{t}}{d t}=\left\{-r b_{0} \frac{e^{-r T}}{1-e^{-r T}}+\left(w^{H}-w^{L}\right)\left(\frac{e^{-r T^{\prime}}-e^{-r T}}{1-e^{-r T}}\right)\right\} r e^{r t} \\
\frac{d^{2} s_{t}}{d t^{2}}=\left\{-r b_{0} \frac{e^{-r T}}{1-e^{-r T}}+\left(w^{H}-w^{L}\right)\left(\frac{e^{-r T^{\prime}}-e^{-r T}}{1-e^{-r T}}\right)\right\} r^{2} e^{r t}
\end{gathered}
$$

so that, if $b_{0}$ is sufficiently small, bond-holdings rise, and at an accelerating rate, until time $T$. Figure11.2 shows this path. This is consumption smoothing: since the current wage is higher than the future wage, the agent optimally accumulates assets. 
Figure 11.2 Saving when income is high
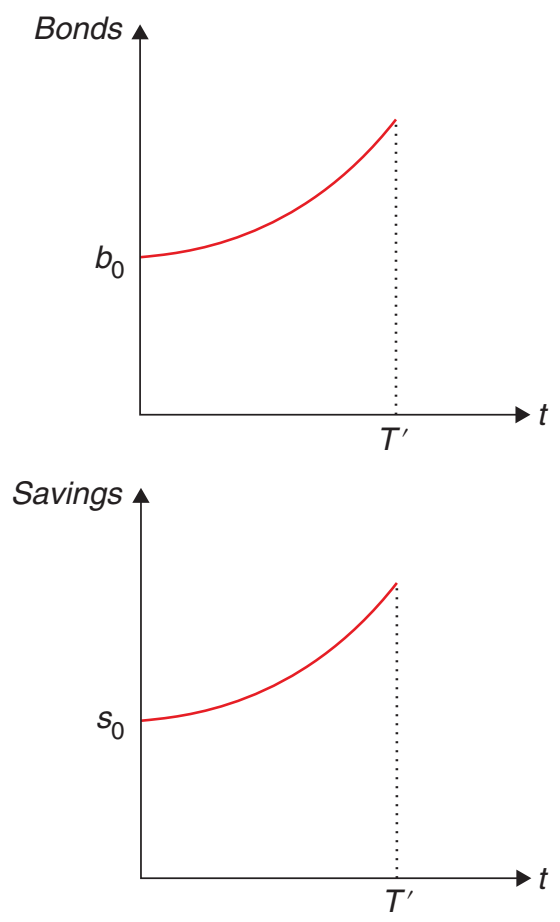

\section{3 | The life-cycle hypothesis}

The most notable application of the model with non-constant labour income is that of consumption over the life cycle. Assume $b_{0}=0$, and also that income follows

$$
w_{t}=\left\{\begin{array}{l}
w>0,0 \leq t<T^{\prime} \\
0, T^{\prime} \leq t<T
\end{array}, T^{\prime}<T\right.
$$

so that now the worker-consumer works for the first $T^{\prime}$ periods of his life, and is retired for the remaining $T-T^{\prime}$ periods.

Then, consumption is simply given by (11.29) with $b_{0}=0, w^{H}=w, w^{L}=0$ :

$$
c^{*}=w\left(\frac{1-e^{-r T^{\prime}}}{1-e^{-r T}}\right)<w
$$

so that consumption per instant is less than the wage.

Let us now figure out what bond-holdings are during working years $\left(t \leq T^{\prime}\right)$. Looking at (11.32), and using (11.38), we can see that 


$$
\begin{aligned}
& b_{t}=\int_{0}^{t} w e^{r(t-s)} d s-\left(e^{r t}-1\right) \frac{w}{r}\left(\frac{1-e^{-r T^{\prime}}}{1-e^{-r T}}\right) \Rightarrow \\
& b_{t}=\frac{w e^{r t}}{r}\left[1-e^{-r t}\right]-\left(e^{r t}-1\right) \frac{w}{r}\left(\frac{1-e^{-r T^{\prime}}}{1-e^{-r T}}\right) \Rightarrow \\
& b_{t}=\frac{w}{r}\left[e^{r t}-1\right]-\left(e^{r t}-1\right) \frac{w}{r}\left(\frac{1-e^{-r T^{\prime}}}{1-e^{-r T}}\right) \Rightarrow \\
& b_{t}=\frac{w}{r}\left[e^{r t}-1\right]\left[\frac{\left(1-e^{-r T}\right)-\left(1-e^{r T^{\prime}}\right)}{1-e^{-r T}}\right] \Rightarrow \\
& b_{t}=\frac{w}{r}\left(e^{r t}-1\right)\left(\frac{e^{-r T^{\prime}}-e^{-r T}}{1-e^{-r T}}\right) .
\end{aligned}
$$

By the same token, savings during the working years $\left(t \leq T^{\prime}\right)$ can be obtained simply by differentiating this expression with respect to time:

$$
s_{t} \equiv \frac{d b_{t}}{d t}=w e^{r t}\left(\frac{e^{-r T^{\prime}}-e^{-r T}}{1-e^{-r T}}\right)
$$

so that

$$
\begin{gathered}
\frac{d s_{t}}{d t} \equiv \frac{d^{2} b_{t}}{d t^{2}}=r w e^{r t}\left(\frac{e^{-r T^{\prime}}-e^{-r T}}{1-e^{-r T}}\right)>0 \\
\frac{d^{2} s_{t}}{d t^{2}}=r^{2} w e^{r t}\left(\frac{e^{r T^{\prime}}-e^{-r T}}{1-e^{-r T}}\right)>0 .
\end{gathered}
$$

What happens after the time of retirement $T^{\prime}$ ? To calculate bond-holdings, notice that for $t \geq T^{\prime}$, (11.25) gives

$$
b_{t}=\frac{w}{r}\left(1-e^{r(t-T)}\right)\left(\frac{1-e^{-r T^{\prime}}}{1-e^{-r T}}\right)
$$

so that

$$
\begin{gathered}
s_{t} \equiv \frac{d b_{t}}{d t}=-w e^{r(t-T)}\left(\frac{1-e^{-r T^{\prime}}}{1-e^{-r T}}\right)<0 \\
\frac{d s_{t}}{d t} \equiv \frac{d^{2} b_{t}}{d t^{2}}=-r w e^{r(t-T)}\left(\frac{1-e^{-r T^{\prime}}}{1-e^{-r T}}\right)<0 \\
\frac{d^{2} s_{t}}{d t^{2}}=-r^{2} w e^{r(t-T)}\left(\frac{1-e^{-r T^{\prime}}}{1-e^{-r T}}\right)<0
\end{gathered}
$$

so that savings decrease over time.

Figure 11.3 shows this path. The agent optimally accumulates assets until retirement time $T^{\prime}$, then depletes them between time $T^{\prime}$ and time of death $T$. This is the basic finding of the life-cycle hypothesis of Modigliani and Brumberg (1954). ${ }^{2}$ 
Figure 11.3 The life-cycle hypothesis

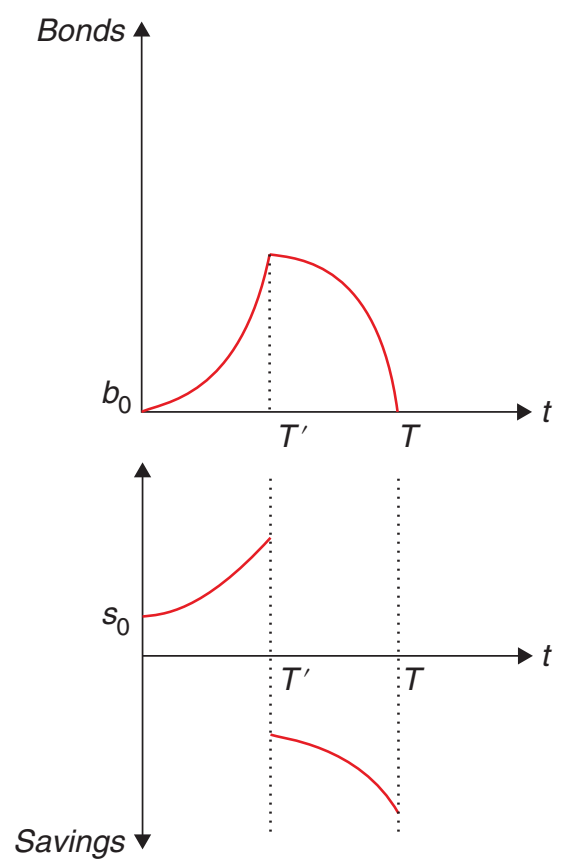

Of course, the life-cycle hypothesis is quite intuitive. One way or the other we all plan for retirement (or trust the government will). Scholz et al. (2006) show that $80 \%$ of the households over age 50 had accumulated at least as much wealth as a life-cycle model prescribes, and the the wealth deficit of the remaining $20 \%$ is relatively small, thus providing support for the model. On the other hand, many studies have also found that consumption falls at retirement. For example, Bernheim et al. (2001) show that there is a drop in consumption at retirement and that it is larger with families with a lower replacement rates from Social Security and pension benefits. This prediction is at odds with the lifecycle hypothesis.

\section{Notes}

${ }^{1}$ Do you remember our discussion of the open-economy Ramsey model, and the implications of $r>\rho$ or $r<\rho$ ?

${ }^{2}$ What explains the curvature? In other words, why is it that the individual accumulates at a faster rate as she approaches retirement, and then decumulates at a faster rate as she approaches death? The intuition is that, because of her asset accumulation, the individual's interest income increases as she approaches retirement - for a constant level of consumption, that means she saves more and accumulates faster. the flip-side of this argument happens close to the death threshold, as interest income gets lower and dissaving intensifies as a result. 


\section{References}

Bernheim, B. D., Skinner, J., \& Weinberg, S. (2001). What accounts for the variation in retirement wealth among U.S. households? American Economic Review, 91(4), 832-857.

Friedman, M. (1957). The permanent income hypothesis. A theory of the consumption function (pp. 20 37). Princeton University Press.

Modigliani, F. \& Brumberg, R. (1954). Utility analysis and the consumption function: An interpretation of cross-section data. Franco Modigliani, 1(1), 388-436.

Scholz, J. K., Seshadri, A., \& Khitatrakun, S. (2006). Are Americans saving "optimally" for retirement? Journal of Political Economy, 114(4), 607-643. 


\section{Consumption under}

\section{uncertainty and macro finance}

In the previous chapter we discussed optimal consumption in a world with certainty. The results basically came down to having people choose a consumption path as stable as possible. To estimate this sustainable level of consumption they take into account future income, net of the bequests they plan to hand over to their children.

There are two dimensions in which this strong result may be challenged. One has to do with uncertainty. Uncertainty may affect expected future income or the return of assets. The second is about preferences themselves. What happens if people have an unusually high preference for present consumption? We will discuss both problems in this chapter. We will see that uncertainty changes the conclusion in a fundamental way: it tilts the path upwards. Faced with uncertainty, people tend to be more cautious and save more than the permanent income hypothesis would suggest. Present bias delivers the opposite result, that people tend to overconsume and enter time inconsistent consumption paths. This rises a whole new set of policy implications.

We end this chapter by introducing a whole new topic, here succinctly sketched to get a flavour. In traditional finance, we typically study portfolio (the realm of asset management) or financing decisions (the realm of corporate finance) based on asset prices. But these asset prices have to make sense given the desired consumption and saving decisions of the individuals in the economy. The area of macro finance puts these two things together. Because asset demands derive directly from consumption decisions, we can flip the problem and ask: given the consumption decisions what are the equilibrium asset prices? The area of macro finance has been a very fertile area of research in recent years.

\subsection{Consumption with uncertainty}

Consumption with uncertainty needs to deal with the uncertainty of future outcomes. The value function $V_{t}\left(b_{t}\right)=\operatorname{Max}_{c_{t}}\left[u\left(c_{t}\right)+\frac{1}{1+\rho} E_{t} V_{t+1}\left(b_{t+1}\right)\right]$ will be a useful instrument to estimate optimal consumption paths.

The analysis of consumption under uncertainty is analogous to that under certainty with the difference that now we will assume that consumers maximise expected utility rather than just plain utility. As it

\section{How to cite this book chapter:}

Campante, F., Sturzenegger, F. and Velasco, A. 2021. Advanced Macroeconomics: An Easy Guide.

Ch. 12. 'Consumption under uncertainty and macro finance', pp. 171-188. London: LSE Press.

DOI: https://doi.org/10.31389/lsepress.ame.l License: CC-BY-NC 4.0. 
turns out, it is more convenient to analyse the case with uncertainty in discrete, rather than continuous, time. The utility that the consumer maximises in this case is

$$
\begin{aligned}
& \max E\left[\sum_{t=0}^{T} \frac{1}{(1+\rho)^{t}} u\left(c_{t}\right)\right], \\
& \text { s.t. } b_{t+1}=\left(w_{t}+b_{t}-c_{t}\right)(1+r) .
\end{aligned}
$$

The uncertainty comes from the fact that we now assume labour income $w_{t}$ to be uncertain. ${ }^{1}$ How do we model individual behaviour when facing such uncertainty? When we impose that individuals use the mathematical expectation to evaluate their utility we are assuming that they have rational expectations: they understand the model that is behind the uncertainty in the economy, and make use of all the available information in making their forecasts. (Or, at the very least, they don't know any less than the economist who is modelling their behaviour.) As we will see time and again, this will have very powerful implications.

Let us start with a two-period model, not unlike the one that we used when analysing the OLG model. As you will recall and can easily verify, the FOC looks like this:

$$
u^{\prime}\left(c_{1}\right)=\left(\frac{1+r}{1+\rho}\right) E_{1}\left[u^{\prime}\left(c_{2}\right)\right]
$$

This FOC generalises to the case of many periods, with exactly the same economic intuition:

$$
u^{\prime}\left(c_{t}\right)=\left(\frac{1+r}{1+\rho}\right) E_{t}\left[u^{\prime}\left(c_{t+1}\right)\right] .
$$

This is our Euler equation for optimal consumption.

To see how this helps us find the consumption level in a multiperiod framework, we use the tools of dynamic programming, which you can briefly review in the math appendix at the end of the book. We show there that intertemporal problems can be solved with the help of a Bellman equation. The Bellman equation rewrites the optimisation problem as the choice between current utility and future utility. Future utility, in turn, is condensed in the value function that gives the maximum attainable utility resulting from the decisions taken today. In short:

$$
V_{t}\left(b_{t}\right)=\operatorname{Max}_{c_{t}}\left[u\left(c_{t}\right)+\frac{1}{1+\rho} E_{t} V_{t+1}\left(b_{t+1}\right)\right] .
$$

The optimising condition of the Bellman equation (maximise relative to $c_{t}$ and use the budget constraint) is

$$
u^{\prime}\left(c_{t}\right)=E_{t}\left[\frac{1+r}{1+\rho} V_{t+1}^{\prime}\left(b_{t+1}\right)\right],
$$

but remember that $V^{\prime}\left(b_{t}\right)=u^{\prime}\left(c_{t}\right)$ along the optimal path. The intuition is that when the value function is optimised relative to consumption, the marginal value of the program along the optimised path has to be the marginal utility of consumption (see our mathematical appendix to refresh the intuition). But then (12.6) becomes (12.4). In a nutshell, the key intuition of dynamic programming, captured by the Bellman equation is that you can break a multi-period (potentially infinite) problem into a sequence of two-period problems where you choose optimally today, making sure that your decisions today make sense when measured against future utility, and then again all the way to eternity if necessary. 


\subsection{1 | The random walk hypothesis}

With quadratic utility we find that $c_{t+1}=c_{t}+\varepsilon_{t+1}$, the random walk hypothesis of consumption. Changes in consumption levels should be unpredictable.

Suppose utility is quadratic ${ }^{2}$, that is

$$
u\left(c_{t}\right)=c_{t}-\frac{a}{2} c_{t}^{2} .
$$

Here things become a bit simpler as marginal utility is linear:

$$
u^{\prime}\left(c_{t}\right)=1-a c_{t} .
$$

This implies that

$$
1-a c_{t}=\frac{(1+r)}{(1+\rho)} E_{t}\left[1-a c_{t+1}\right] .
$$

If we keep assuming that $r=\rho$ as we've done before, it follows that

$$
a c_{t}=E_{t}\left[a c_{t+1}\right]
$$

or, more simply, that

$$
c_{t}=E_{t}\left[c_{t+1}\right] .
$$

Equation (12.11) can be depicted as the following stochastic process for consumption:

$$
c_{t+1}=c_{t}+\varepsilon_{t+1},
$$

where $\varepsilon_{t}$ is a zero-mean random disturbance (also called white noise).

A stochastic process that looks like this is called a random walk, for this reason this description of consumption (due to Hall 1978) is called the random walk hypothesis of consumption. It is a very strong statement saying that only unexpected events can change the consumption profile - all information that is already known must have already been taken into consideration and therefore will not change consumption when it happens. This result, one of the early applications of the rational expectations assumption, is a powerful empirical implication that can easily be tested.

\subsection{2 $\quad$ Testing the random walk hypothesis}

Empirical evidence does not support fully the random walk hypothesis of consumption.

A large number of papers have tried to assess the random walk hypothesis. One classical contribution is the Shea (1995) test on whether predictable changes in income are or are not related to predictable changes in consumption. He looks into long-term union contracts which specified in advance changes in wages. He then runs the consumption growth on the income growth. The theory suggests the coefficient should be zero, but the number comes out to be .89 .

Of course it can very well be that this is because people have liquidity constraints. So Shea runs the test on people that have liquid assets and could thus borrow from themselves. These people cannot have a liquidity constraint. Yet he still finds the same result. Then he splits people into two groups: those that are facing declining incomes and those for which income is growing. Those facing 
a future fall in income should reduce their consumption and save, so you should not find an effect of liquidity constraints. Yet, it seems that, again, changes in current income help predict changes in consumption.

This type of exercises has been replicated in many other contexts. Ganong and Noel (2019) for example, find that household consumption falls 13 percent when households receiving unemployment benefits reach the (anticipated) end of their benefits. Food stamp recipients and social security beneficiaries also show monthly patterns of consumption that are related to the payment cycle.

\subsection{3 | The value function}

The value function is a useful tool to estimate optimal paths. We review two approaches to solve for these paths: guess and replace and value function iteration.

While important, the quadratic case is a very special case that allows a simple characterisation of the consumption path. Can we solve for more general specifications? Here is where the value function approach comes in handy. There are several ways of using the value function to approximate the optimal path. If the problem is finite, one can work the problem backwards from the last period. But this is not very useful in problems with no terminal time, which is our typical specification. One way to approach the problem is to simply guess the value function. This can be done in simple cases, but is not typically available, particularly because no problem should rely on having a genius at hand that can figure out the solution beforehand. An alternative is to do an iteration process that finds the solution through a recursive estimation. This is easier, and may actually deliver a specific solution in some cases. However, this approach can also be implemented by a recursive estimation using computational devices. So that you get a sense of how these methods work, we will solve a very simple problem through the guess and replace solution, and then through the value function iteration method. It is a bit tedious but will allow you to get a feel of the methodology involved.

\section{A guess and replace example}

Imagine we take the special case of $u\left(c_{t}\right)=\log \left(c_{t}\right)$ and guess (spoiler: we already know it will work!) the form

$$
V\left(b_{t}\right)=a \log \left(b_{t}\right)+d,
$$

that is, with a form equal to utility and with constants $a$ and $d$ to be determined. If this is the value function, then consumption has to maximise

$$
\ln \left(c_{t}\right)+\frac{1}{1+\rho} E\left[a \log \left(b_{t+1}\right)+d\right] .
$$

Remember that $b_{t+1}=\left(b_{t}-c_{t}\right)(1+r)$, as in (12.2) where we just assumed $w$ to be zero to lighten up notation. Now take the derivative of (12.14) relative to $c_{t}$. We leave this computation to you but it is easy and you should find that this gives

$$
c_{t}=\frac{b_{t}}{1+\frac{a}{1+\rho}} .
$$


Are we done? No, because we need to find the value of $a$. To do this we are going to use our guess (12.13) using (12.5). This means writing

$$
a \log \left(b_{t}\right)+d=\log \left(\frac{b_{t}}{1+\frac{a}{1+\rho}}\right)+\frac{1}{1+\rho}\left[a \log \left[\left(b_{t}-\frac{b_{t}}{1+\frac{a}{1+\rho}}\right)(1+r)\right]+d\right] .
$$

What we have done is write the value function on the left and replacing optimal consumption from (12.15), and $b_{t+1}$ from the budget constraint (using optimal consumption again). The expectation goes because all variables are now dated at $t$. Now the log specification makes things simple. Just factor out the logs on the right hand side and pile up all the coefficients of $b_{t}$ on the right-hand side. If the value function is right, these coefficients should be equal to $a$ the coefficient of $b_{t}$ in the value function on the left. After you clear this out, you will get the deceptively simple equivalence

$$
a=1+\frac{a}{1+\rho},
$$

which is an equation that you can use to solve for $a$. Trivial algebra gives that $a=\frac{1+\rho}{\rho}$ which, introduced in (12.15), gives our final solution

$$
c_{t}=\frac{\rho}{1+\rho} b_{t}
$$

This, by now is an expected result. You consume a fraction of your current wealth. (The log specification cancels the effect of returns on consumption and thus simplifies the solution).

\section{Iteration}

Now, let's get the intuition for the solution by iterating the value function. Let's imagine we have no idea what the value function could be, so we are going the make the arbitrary assumption that it is zero. Let us track the iteration by a subindex on the value function $1,2,3 \ldots$ So, with this assumption $V_{0}=0$. So our first iteration implies that

$$
V_{1}\left(b_{t}\right)=\operatorname{Max}_{c_{t}}\left[\log \left(c_{t}\right)+\frac{1}{1+\rho} 0\right],
$$

subject to the budget constraint in (12.2). The solution to this problem is trivial. As assets have no value going forward, $c_{t}=b_{t}$, so our $V_{1}=\log \left(b_{t}\right)$. Now let's iterate to the second stage by defining $V_{2}$ using $V_{1}$. This means

$$
V_{2}=\operatorname{Max}_{c_{t}}\left[\log \left(c_{t}\right)+\frac{1}{1+\rho} \log \left(b_{t+1}\right)\right]=\operatorname{Max}_{c_{t}} \log \left(c_{t}\right)+\frac{1}{1+\rho} \log \left[\left(b_{t}-c_{t}\right)(1+r)\right] .
$$

Again, maximise this value function relative to $c_{t}$. This is not complicated and you should get that $c_{t}^{*}=\frac{b_{t}(1+\rho)}{(2+\rho)}$. The more tricky part is that we will use this to compute our $V_{2}$ equation. Replace $c_{t}^{*}$ in (12.20) to get

$$
V_{2}=\log \left(c_{t}^{*}\right)+\frac{1}{1+\rho} \log \left[\left(b_{t}-c_{t}^{*}\right)(1+r)\right]
$$

Notice that the log will simplify things a lot so this will end up looking like

$$
V_{2}=\left(1+\frac{1}{1+\rho}\right) \log \left(b_{t}\right)+\log \left[\frac{1+\rho}{2+\rho}\right]+\frac{1}{1+\rho} \log \left[\frac{1}{2+\rho}(1+r)\right]=\left(1+\frac{1}{1+\rho}\right) \log \left(b_{t}\right)+\theta_{2}
$$


The important part is the one that multiplies $b_{t}$ the other is a constant which we see quickly becomes unwieldy. To finalise the solution let's try this one more time. Our last iteration uses our $V_{2}$ to compute $V_{3}$ (we omit the constant term):

$$
V_{3}=\operatorname{Max}_{c_{t}}\left[\log \left(c_{t}\right)+\left(1+\frac{1}{1+\rho}\right) \log \left(b_{t+1}\right)\right] .
$$

Use again the budget constraint and maximise respect to $c_{t}$. You should be able to find that

$$
c_{t}^{*}=\frac{1}{1+\frac{1}{1+\rho}+\frac{1}{(1+\rho)^{2}}} b_{t} .
$$

We leave, for the less fainthearted, the task of replacing this in (12.23) to compute the final version of $V_{3}$. Fortunately, we do not need to do this. You can see a clear pattern in the solutions for $c_{t}^{*}$. If you iterate and iterate to infinity, the denominator will add up to $\frac{1+\rho}{\rho}$. This implies that the solution is $c_{t}=\frac{\rho}{1+\rho} b_{t}$. Not surprisingly, the same as in (12.18).

\subsection{4 | Precautionary savings}

When faced with uncertainty consumers will be more precautionary, tilting the consumption profile upwards throughout their lifetimes. The Caballero model provides a simple specification that computes that slope and shows how it increases with volatility.

Let's ask ourselves how savings and consumption react when uncertainty increases. Our intuition suggests that an increase in uncertainty should tilt the balance towards more savings, a phenomenon dubbed precautionary savings. To illustrate how this works we go back to our Euler equation:

$$
u^{\prime}\left(c_{t}\right)=\frac{1}{1+\rho} E_{t}\left[\left(1+r_{t+1}^{i}\right) u^{\prime}\left(c_{t+1}\right)\right] .
$$

Assume again that $r_{t+1}^{i}=\rho=0$, to simplify matters. Thus, the condition reduces to (we've seen this before!):

$$
u^{\prime}\left(c_{t}\right)=E_{t}\left[u^{\prime}\left(c_{t+1}\right)\right] .
$$

Now assume, in addition to the typical $u^{\prime}>0$ and $u^{\prime \prime}<0$, that $u^{\prime \prime \prime}>0$. This last condition is new and says that marginal utility is convex. This seems to be a very realistic assumption. It means that the marginal utility of consumption grows very fast as consumption approaches very low levels. Roughly speaking, people with convex marginal utility will be very concerned with very low levels of consumption. Figure 12.1 shows how marginal utility behaves if this condition is met.

Notice that for a quadratic utility

$$
E\left[u^{\prime}(c)\right]=u^{\prime}(E[c])
$$

But the graph shows clearly that if marginal utility is convex then

$$
E\left[u^{\prime}(c)\right]>u^{\prime}(E[c]),
$$

and that the stronger the convexity, the larger the difference. The bigger $E\left[u^{\prime}(c)\right]$ is, the bigger $c_{t+1}$ needs to be to keep the expected future utility equal to $u^{\prime}(c)$, the marginal utility of consumption today. Imagine, for example that you expect one of your consumption possibilities for next period 
Figure 12.1 Precautionary savings

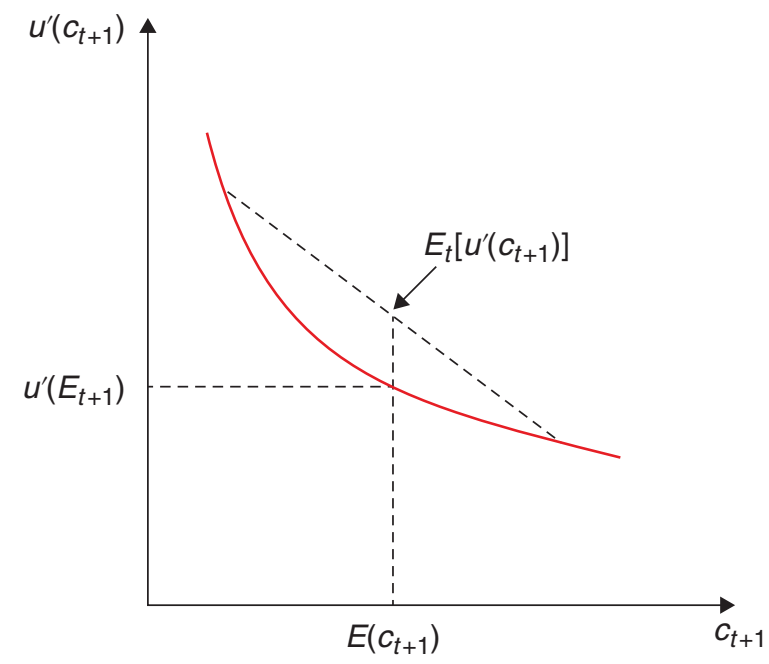

to be zero. If marginal utility at zero is $\infty$ then $E\left[u^{\prime}(c)\right]$ will also be $\infty$, and therefore you want to increase future consumption as much as possible to bring this expected marginal utility down as much as possible. In the extreme you may choose not to consume anything today! This means that you keep some extra assets, a buffer stock, to get you through the possibility of really lean times. This is what is called precautionary savings. Precautionary savings represents a departure from the permanent income hypothesis, in that it will lead individuals to save more than would be predicted by the latter, because of uncertainty.

\section{The Caballero model}

Caballero (1990) provides a nice example that allows for a simple solution. Consider the case of a constant absolute risk aversion function.

$$
u\left(c_{t}\right)=-\frac{1}{\theta} e^{-\theta c_{t}}
$$

Assuming that the interest rate is equal to the discount rate for simplification, this problem has a traditional Euler equation of the form

$$
e^{-\theta c_{t}}=E_{t}\left[e^{-\theta c_{t+1}}\right]
$$

Caballero proposes a solution of the form

$$
c_{t+1}=\Gamma_{t}+c_{t}+v_{t+1},
$$

were $v$ is related to the shock to income, the source of uncertainty in the model. Replacing in the Euler equation gives

$$
e^{-\theta c_{t}}=E_{t}\left[e^{-\theta\left[\Gamma_{t}+c_{t}+v_{t+1}\right]}\right],
$$


which, taking logs, simplifies to

$$
\theta \Gamma_{t}=\log E_{t}\left[e^{-\theta v_{t+1}}\right]
$$

If $v$ is distributed $N\left(0, \sigma^{2}\right)$, then we can use the fact that $E e^{x}=e^{E x+\frac{\sigma_{x}^{2}}{2}}$ to find the value of $\Gamma$ (as the value is constant, we can do away with the subscript) in (12.33):

$$
\theta \Gamma=\log \left[e^{\frac{\theta^{2} \sigma_{v}^{2}}{2}}\right],
$$

or, simply,

$$
\Gamma=\frac{\theta \sigma_{v}^{2}}{2} .
$$

This is a very simple expression. It says that even when the interest rate equals the discount rate the consumption profile is upward sloping. The higher the variance, the higher the slope.

The precautionary savings hypothesis is also useful to capture other stylised facts: families tend to show an upward-sloping consumption path while the uncertainties of their labour life get sorted out. Eventually, they reach a point were consumption stabilises and they accumulate assets. Gourinchas and Parker (2002) describe these dynamics. Roughly the pattern that emerges is that families have an increasing consumption pattern until sometime in the early 30 s, after which consumption starts to flatten.

\subsection{New frontiers in consumption theory}

Consumption shows significant deviations from the optimal intertemporal framework. One such deviation is explained by early bias, a tendency to give a stronger weight to present consumption. This leads to time inconsistency in consumption plans. Consumption restrictions, such as requesting a stay period before consumption, may solve the problem.

Though our analysis of consumption has taken us quite far, many consumption decisions cannot be suitably explained with the above framework as it has been found that consumers tend to develop biases that move their decisions away from what the model prescribes. For example, if a family receives an extra amount of money, they will probably allocate it to spending on a wide range of goods and maybe save at least some of this extra amount. Yet, if the family receives the same amount of extra money on a discount on food purchases, it is found that they typically increase their food consumption more (we could even say much more) than if they would have received cash. Likewise, many agents run up debts on their credit cards when they could pull money from their retirement accounts at a much lower cost.

One way of understanding this behaviour is through the concept of mental accounting, a term coined by Richard Thaler, who won the Nobel Prize in economics in 2017. In Thaler's view, consumers mentally construct baskets of goods or categories. They make decisions based on these categories not as if they were connected by a unique budget constraint, but as if they entailed totally independent decisions.

A similar anomaly occurs regarding defaults or reference points which we mentioned at the end of our Social Security chapter. Imagine organising the task of allocating yellow and red mugs to a 
group of people. If you ask people what colour they would like their mugs to be, you will probably get a uniform distribution across colours, say $50 \%$ choose yellow and $50 \%$ choose red. Now allocate the mugs randomly and let people exchange their mugs. When you do this, the number of exchanges is surprisingly low. The received mug has become a reference point which delivers utility per-se. This type of reference point explains why agents tend to stick to their defaults. Brigitte Madrian has shown that when a $3 \%$ savings contribution was imposed as default (but not compulsory), six months later $86 \%$ of the workers remained within the plan, relative to $49 \%$ if no plan had been included as default, and $65 \%$ stuck to the $3 \%$ contribution vs only $4 \%$ choosing that specific contribution when such percentage was not pre-established. (In fact, Madrian shows that the effect of defaults is much stronger than providing economic incentives for savings, and much cheaper!)

One of the biases that has received significant attention is what is called present bias. Present bias is the tendency to put more weight to present consumption relative to future consumption. Let's discuss the basics of this idea.

\subsection{1 | Present bias}

We follow (Beshears et al. 2006) in assuming a model with three periods. In period zero the consumer can buy (but not consume) an amount $c_{0} \geq 0$ of a certain good. In period one, the consumer can buy more of this good $\left(c_{1} \geq 0\right)$ and now consume it. Total consumption is

$$
c=c_{0}+c_{1} \text {. }
$$

In period 2, the consumer spends whatever was left on other goods $x$. The budget constraint can be written as

$$
1+T=c_{0}\left(1+\tau_{0}\right)+c_{1}\left(1+\tau_{1}\right)+x,
$$

where $\tau_{0}$ and $\tau_{1}$ are taxes over $c_{0}$ and $c_{1}$ and $T$ is a lump sum transfer. Income is assumed equal to 1 . $T=\overline{c_{0}} \tau_{0}+\overline{c_{1}} \tau_{1}$, where the bars indicate the average values for each variable. As the economy is large, these variables are unchanged by the individual decision to consume. Introducing taxes and lump sum transfers is not necessary, but will become useful below to discuss policy. Summing up, the structure is:

- Period 0: buys $c_{0}$ at after tax price of $\left(1+\tau_{0}\right)$

- Period 1: buys an additional amount $c_{1}$ at an after tax price of $\left(1+\tau_{1}\right)$. Consumes $c=c_{0}+c_{1}$

- Period 2: buys and consumes good $x$ at price 1 with the remaining resources $1+T-c_{0}\left(1+\tau_{0}\right)-$ $c_{1}\left(1+\tau_{1}\right)$.

\section{Time inconsistency in consumer's behaviour}

The key assumption is that the consumer has a quasi-hyperbolic intertemporal discount factor with sequence: $1, \beta \frac{1}{1+\rho}, \beta\left(\frac{1}{1+\rho}\right)^{2}, \beta\left(\frac{1}{1+\rho}\right)^{3}$. We assume $0 \leq \beta \leq 1$ to capture the fact that the consumer discounts more in the short run than the long run. As we will see, this will produce preferences that are not consistent over time. In addition, we will assume the good provides immediate satisfaction but a delayed cost (a good example would be smoking or gambling).

Let's assume that the utility of consuming $c$ is

$$
E u_{0}(c, x)=E\left[\beta \frac{1}{1+\rho}(\alpha+\Delta) \log (c)-\beta\left(\frac{1}{1+\rho}\right)^{2} \alpha \log (c)+\beta\left(\frac{1}{1+\rho}\right)^{2} x\right],
$$


where $\Delta$ and $\alpha$ are fixed taste-shifters. The utility from $x$ is assumed linear, as it represents all other goods.

For simplicity, we assume $\frac{1}{1+\rho}=1$. Expected utility as seen in period zero is

$$
E u_{0}(c, x)=E \beta[\Delta \log (c)+x] .
$$

Notice that the delayed consumption penalty disappears when seen from afar. In period 1, the utility function is

$$
u_{1}(c, x)=(\Delta+\alpha) \log (c)-\beta \alpha \log (c)+\beta x .
$$

Notice that relative utility between the good $c$ and $x$ is not the same when seen at time 0 and when seen at time 1. At period zero, the other goods were not penalised relative to $c$, but from the perspective of period 1 the benefits of consumption are stronger because satisfaction is immediate relative to the delayed cost and relative to the utility of other goods to which the present bias applies. This will lead to time inconsistency.

\section{Precommitment}

Imagine consumption is determined at time zero and for now $\tau_{0}=\tau_{1}=0$. This would give the optimal consumption ex-ante. Maximising (12.39) subject to (12.37) can easily be shown to give

$$
\frac{\Delta}{c}=1 .
$$

Notice that this implies $c=\Delta$ and $x=1-\Delta$. Thus, expected utility as of period 0 is

$$
E u_{0}(c, x)=E \beta[\Delta \log (\Delta)]+\beta(1-\Delta) .
$$

This will be our benchmark.

\section{The free equilibrium}

Keeping $\tau_{0}=\tau_{1}=0$, now imagine that consumption is chosen in period 1 . This is obtained maximising (12.40) subject to (12.37). This gives

$$
\frac{\alpha(1-\beta)+\Delta}{c}=\beta .
$$

Notice that now $c=\frac{\alpha(1-\beta)+\Delta}{\beta}$ which can easily be shown to be higher than the value obtained in the precommitment case. From the perspective of period 0 , the marginal utility of $c$ is now smaller than the utility of consuming $x$. Thus, this free equilibrium is not first-best optimal at least from the perspective of period zero.

\section{Optimal regulation: Las Vegas or taxation?}

Are there policies that may restore the first-best equilibrium from the perspective of period zero utility?

One option is an early decision rule that allows the purchase of $c$ only during period zero. This is like having an infinite tax in period 1. A well-known application of this policy is, for example, to move gambling activities far away from living areas (e.g. Las Vegas). This way, the consumer decides 
on the consumption without the urgency of the instant satisfaction. This case trivially replicates the precommitment case above and need not be repeated here.

This outcome can also be replicated with optimal taxation. To see how, let's consider a tax policy of the form $\tau_{0}=\tau_{1}=\tau$. In order to solve this problem, let's revisit the maximisation of (12.40) subject to (12.37). The solution for $c$ gives

$$
c=\frac{\alpha(1-\beta)+\Delta}{\beta(1+\tau)} .
$$

To obtain the optimal $\tau$, replace (12.44) in (12.39) and maximise with respect to $\tau$. The first order condition gives :

$$
-\frac{\Delta}{1+\tau}+\frac{\alpha(1-\beta)+\Delta}{\beta(1+\tau)^{2}}=0
$$

which gives the optimal tax rate

$$
\tau=\left(\frac{\alpha}{\Delta}+1\right)\left(\frac{1}{\beta}-1\right),
$$

which delivers $c=\Delta$, replicating the optimal equilibrium. So a tax policy can do the trick. In fact, with no heterogeneity both policies are equivalent.

Things are different if we allow for heterogeneity. Allow now for individual differences in $\Delta$. We can repeat the previous steps replacing $\Delta$ with $E[\Delta]$, and get the analogous conditions

$$
\beta\left[-\frac{E[\Delta]}{1+\tau}+\frac{\alpha(1-\beta)+E[\Delta]}{\beta(1+\tau)^{2}}\right]=0,
$$

which gives the same tax rate

$$
\tau=\left(\frac{\alpha}{E(\Delta)}+1\right)\left(\frac{1}{\beta}-1\right) .
$$

With heterogeneity, consumers will move towards the first best but faced with a unique tax rate will consume different amounts. Notice that $\beta[\Delta \log (c)+(1-c)]<\beta[\Delta \log (\Delta)+(1-\Delta)]$ for all $c \neq \Delta$, which happens to the extent that $E[\Delta] \neq \Delta$. As this happens for a nonzero mass of consumers if heterogeneity is going to be an issue at all:

$$
\begin{aligned}
& E u_{0}=E \beta[\Delta \log (c)+1+T-c(1+\tau)]=E \beta[\Delta \log (c)+1-c] \\
&<E \beta[\Delta \log (\Delta)+1-\Delta] .
\end{aligned}
$$

The result is quite intuitive, as each consumer knows its own utility an early decision mechanism is superior to a tax policy because each individual knows his own utility and attains the first best with the early decision mechanism.

These biases have generated significant attention in recent years, generating important policy recommendations. 


\section{3 | Macroeconomics and finance}

While typical corporate finance uses asset prices to explain investment or financing decisions, macrofinance attempts to understand asset prices in a general equilibrium format, i.e. in a way that is consistent with the aggregate outcomes of the economy. The basic pricing equation $r_{t+1}^{i}-r_{t+1}^{f}=\frac{a \cdot \operatorname{cov}\left(1+r_{t+1}^{i}, c_{t+1}\right)}{E_{t}\left(u^{\prime}\left(c_{t+1}\right)\right)}$ is remarkable; expected returns are not associated with volatility but to the correlation with the stochastic discount factor.

We've come a long way in understanding consumption. Now it is time to see if what we have learnt can be used to help us understand what asset prices should be in equilibrium.

To understand this relationship, we can use Lucas's (1978) metaphor: imagine a tree that provides the economy with a unique exogenous income source. What is this tree worth? Optimal consumption theory can be used to think about this question, except that we turn the analysis upside down. Typically, we would have the price of an asset and have the consumer choose how much to hold of it. But in the economy the amount held and the returns of those assets are given because they are what the economy produces. So here we will use the FOCs to derive what price makes those exogenous holdings optimal. By looking at the FOCs at a given equilibrium point as an asset pricing equation allows us to go from actual consumption levels to asset pricing. Let's see an example.

Start with the first order condition for an asset that pays a random return $r_{t+1}^{i}$ :

$$
u^{\prime}\left(c_{t}\right)=\frac{1}{1+\rho} E_{t}\left[\left(1+r_{t+1}^{i}\right) u^{\prime}\left(c_{t+1}\right)\right] \quad \forall i
$$

Remember that

$$
\operatorname{cov}(x, y)=E(x y)-E(x) E(y),
$$

so, applying this equation to (12.51), we have that

$$
u^{\prime}\left(c_{t}\right)=\frac{1}{1+\rho}\left\{E_{t}\left(1+r_{t+1}^{i}\right) E_{t}\left(u^{\prime}\left(c_{t+1}\right)\right)+\operatorname{cov}\left(1+r_{t+1}^{i}, u^{\prime}\left(c_{t+1}\right)\right)\right\} .
$$

This is a remarkable equation. It says that you really don't care about the variance of the return of the asset, but about the covariance of this asset with marginal utility. The variance may be very large, but, if it is not correlated with marginal utility, the consumer will only care about expected values. The more positive the correlation between marginal utility and return means a higher right-hand side, and, therefore, a higher value (more utility). Notice that a positive correlation between marginal utility and return means that the return is high when your future consumption is low. Returns, in short, are better if they are negatively correlated with your income; and if they are, volatility is welcomed!

As simple as it is, this equation has a lot to say, for example, as to whether you should own your house, or whether you should own stocks of the company you work for. Take the example of your house. The return on the house are capital gains and the rental value of your house. Imagine the economy booms. Most likely, prices of property and the corresponding rental value goes up. In these cases your marginal utility is going down (since the boom means your income is going up), so the correlation between returns and marginal utility is negative. This means that you should expect housing to deliver a very high return (because it's hedging properties are not that good). Well, that's right on the dot. Remember our mention to Kaplan et al. (2014) in Chapter 8, who show that housing has an amazingly high return. (There may be other things that play a role in the opposite direction, as home ownership provides a unique sense of security and belonging, which our discussion of precautionary 
savings indicates can be very valuable.). ${ }^{3}$ Buying stocks of the firm you work in is a certain no go, so, to rationalise it, you need to appeal to asymmetric information, or to some cognitive bias that makes you think that knowing more about this asset makes you underestimate the risks. In fact, optimal policy would indicate you should buy the stock of your competitor. ${ }^{4}$

So far, we have been thinking of interest rates as given and consumption as the variable to be determined. However, if all individuals are optimising, equilibrium returns to assets will have to satisfy the same conditions. This means we can think of equation (12.53) as one of equilibrium returns. To make things simple, assume once again that $u(c)=c-\frac{a c^{2}}{2}$. Then (12.53) becomes:

$$
u^{\prime}\left(c_{t}\right)=\frac{1}{1+\rho}\left\{E_{t}\left(1+r_{t+1}^{i}\right) E_{t}\left(u^{\prime}\left(c_{t+1}\right)\right)-a \cdot \operatorname{cov}\left(1+r_{t+1}^{i}, c_{t+1}\right)\right\},
$$

which can also be written as

$$
E_{t}\left(1+r_{t+1}^{i}\right)=\frac{1}{E_{t}\left(u^{\prime}\left(c_{t+1}\right)\right)}\left\{(1+\rho) u^{\prime}\left(c_{t}\right)+a \cdot \operatorname{cov}\left(1+r_{t+1}^{i}, c_{t+1}\right)\right\} .
$$

Notice that for a risk-free asset, for which $\operatorname{cov}\left(1+r_{t+1}^{f}, c_{t+1}\right)=0$, we will have

$$
\left(1+r_{t+1}^{f}\right)=\frac{(1+\rho) u^{\prime}\left(c_{t}\right)}{E_{t}\left(u^{\prime}\left(c_{t+1}\right)\right)} .
$$

Before proceeding, you may want to ponder on an interesting result. Notice that in the denominator you have the expected marginal utility of future consumption. This produces two results. If consumption growth is high, the interest rate is higher (if $c_{t+1}$ is big, its marginal utility is low). But at the same time, notice that if the volatility of consumption is big, then the denominator is bigger (remember our discussion of precautionary savings). To see this, imagine that under some scenarios $c_{t+1}$ falls so much that the marginal utility becomes very large. In higher volatility economies, the risk-free rate will be lower!

So, using (12.55) in (12.56) we obtain

$$
\begin{gathered}
E_{t}\left(1+r_{t+1}^{i}\right)-\left(1+r_{t+1}^{f}\right)=\frac{a \cdot \operatorname{cov}\left(1+r_{t+1}^{i}, c_{t+1}\right)}{E_{t}\left(u^{\prime}\left(c_{t+1}\right)\right)}, \\
E_{t}\left(r_{t+1}^{i}\right)-r_{t+1}^{f}=\frac{a \cdot \operatorname{cov}\left(1+r_{t+1}^{i}, c_{t+1}\right)}{E_{t}\left(u^{\prime}\left(c_{t+1}\right)\right)} .
\end{gathered}
$$

This equation states that the premia of an asset is determined in equilibrium by its covariance with aggregate consumption.

\subsection{1 | The consumption-CAPM}

We show that the basic pricing equation can be written as $r_{t+1}^{i}-r_{t+1}^{f}=\frac{\operatorname{cov}\left(z_{t+1}^{i}, z_{t+1}^{m}\right)}{\operatorname{var}\left(z_{t+1}^{m}\right)}\left[r_{t+1}^{m}-r_{t+1}^{f}\right]$. Risk premia depend on the asset's covariance with market returns with a coefficient called $\beta$ that can be computed by running a regression between individual and market returns. This is the so-called capital asset pricing model (CAPM). 
Consider now an asset called "the market" that covaries negatively with marginal utility of consumption (as the market represents the wealth of the economy, consumption moves with it, and therefore in the opposite direction as the marginal utility of consumption). That is,

$$
u^{\prime}\left(c_{t+1}\right)=-\gamma z_{t+1}^{m} .
$$

Applying (12.58) to this asset, we have

$$
r_{t+1}^{m}-r_{t+1}^{f}=\frac{\gamma \cdot \operatorname{var}\left(z_{t+1}^{m}\right)}{E_{t}\left(u^{\prime}\left(c_{t+1}\right)\right)} .
$$

Consider now an individual asset with return $z_{t+1}^{i}$. Applying the same logic we have that

$$
r_{t+1}^{i}-r_{t+1}^{f}=\frac{\gamma \cdot \operatorname{cov}\left(z_{t+1}^{i}, z_{t+1}^{m}\right)}{E_{t}\left(u^{\prime}\left(c_{t+1}\right)\right)} .
$$

Combining both equations (just replace $E_{t}\left(u^{\prime}\left(c_{t+1}\right)\right)$ from (12.60) into (12.61), we have that

$$
r_{t+1}^{i}-r_{t+1}^{f}=\frac{\operatorname{cov}\left(z_{t+1}^{i}, z_{t+1}^{m}\right)}{\operatorname{var}\left(z_{t+1}^{m}\right)}\left[r_{t+1}^{m}-r_{t+1}^{f}\right] .
$$

You may have seen something very similar to this equation: it is the so-called CAPM, used to determine the equilibrium return of an asset. The formula says that the asset will only get a premia for the portion of its variance that is not diversifiable. An asset can have a very large return, but if the correlation of the return with the market is zero, the asset will pay the risk-free rate in spite of all that volatility! Another way of saying this is that all idiosyncratic (i.e. diversifiable by holding a sufficiently large portfolio) risk is not paid for. This is the reason you should typically not want to hold an individual asset: it will carry a lot of volatility you are not remunerated for. The popularity of the CAPM model also hinges on how easy it is to compute the slope of the risk premia: it is just the regression coefficient obtained from running the return of the asset (relative to the risk free) and the market return. The value of that coefficient is called $\beta$.

This version, derived from the optimal behaviour of a consumer under uncertainty, is often referred to as Consumption-based CAPM (C-CAPM).

\section{\begin{tabular}{l|l} 
12.3.2 & Equity premium puzzle
\end{tabular}}

The premia for equities is given by $E\left(r^{i}\right)-\bar{r}=\theta \operatorname{cov}\left(r^{i}, g^{c}\right)$. But this does not hold in the data unless risk aversion is unreasonably high. This is the so-called equity premium puzzle.

Our asset pricing model can help us think about some asset pricing puzzles that have long left economists and finance practitioners scratching their heads. One such puzzle is the equity premium puzzle.

The puzzle, in the U.S., refers to the fact that equities have exhibited a large premia (around 6\% on average) relative to bonds, and this premia has remained relatively constant for about 100 years. As equities are riskier than bonds a premia is to be expected. But does $6 \%$ make sense? If an asset earns $6 \%$ more than another, it means that the asset value will be $80 \%$ higher at the end of 10 years, $220 \%$ more at the end of 20 years, $1740 \%$ higher at the end of 50 years, and $33.800 \%$ higher at the end of 100 
Figure 12.2 Equity premium puzzle, from Jorion and Goetzmann (1999)

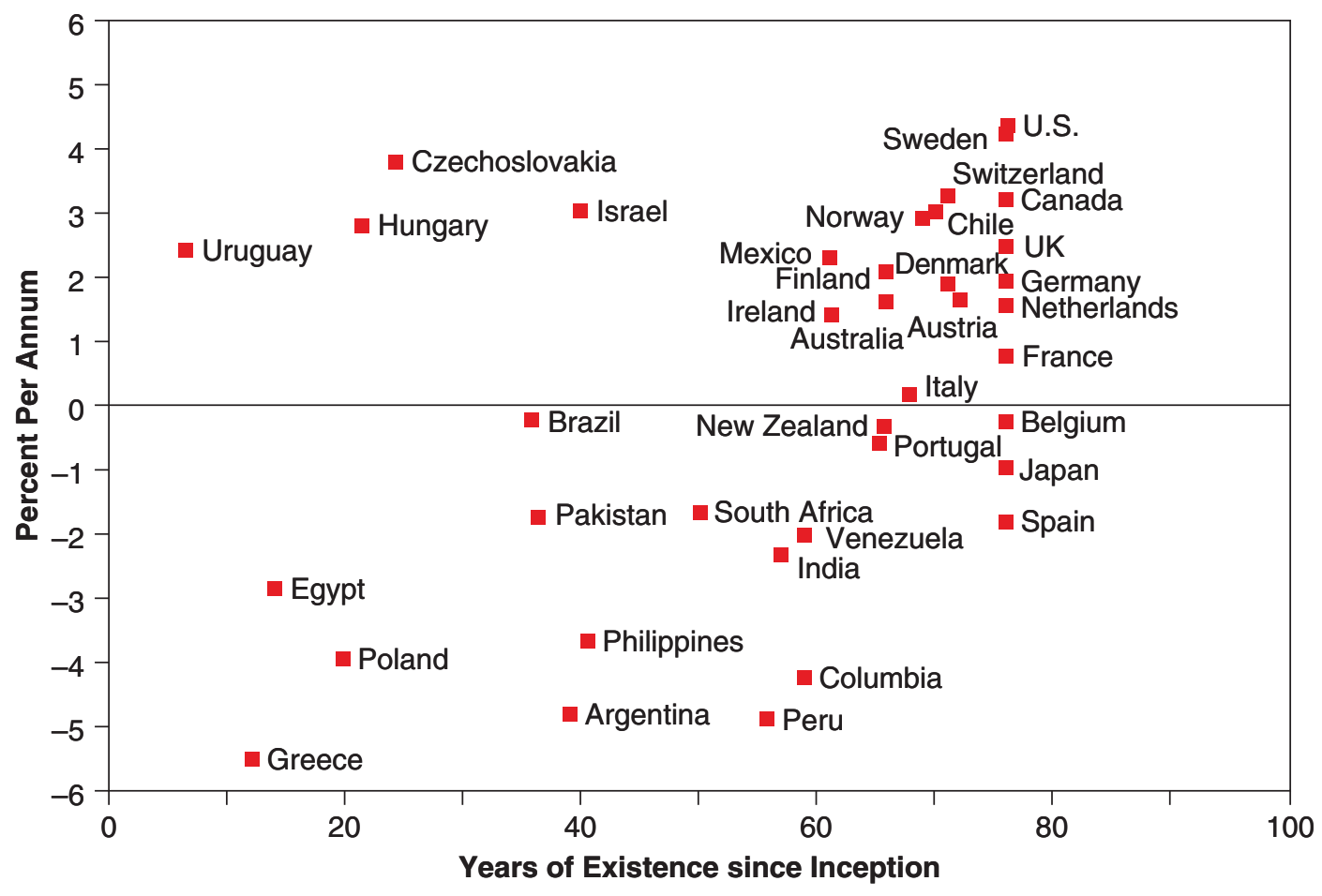

years! You get the point; there is no possible risk aversion coefficient that can deliver these differences as an equilibrium spread.

Figure 12.2, taken from Jorion and Goetzmann (1999), shows that the equity premium puzzle is a common occurrence, but does not appear in all countries. In fact the U.S. seems to be the country where its result is most extreme.

To have more flexibility, we need to move away from a quadratic utility function and use a more general CRRA utility function instead. Now our FOC looks like

$$
c_{t}^{-\theta}=\frac{1}{1+\rho} E_{t}\left[\left(1+r_{t+1}^{i}\right) c_{t+1}^{-\theta}\right]
$$

which can be written as

$$
1+\rho=E_{t}\left[\left(1+r_{t+1}^{i}\right) \frac{c_{t+1}^{-\theta}}{c_{t}^{-\theta}}\right]=E_{t}\left[\left(1+r_{t+1}^{i}\right)\left(1+g^{c}\right)^{-\theta}\right] .
$$

Take a second order expansion of the term within the square brackets on the RHS at $g=r=0$ (notice that in this case the usual $\Delta r$ becomes $r$, and $\Delta g$ becomes $g$ )

$$
\begin{array}{r}
1+\left(1+g^{c}\right)^{-\theta} r+(1+r)(-\theta)\left(1+g^{c}\right)^{-\theta-1} g^{c}+(-\theta)\left(1+g^{c}\right)^{-\theta-1} g^{c} r+ \\
+\frac{1}{2}(1+r)(-\theta)(-\theta-1)\left(1+g^{c}\right)^{-\theta-2}\left(g^{c}\right)^{2} .
\end{array}
$$


At $r=g=0$ (but keeping the deviations), this simplifies to

$$
1+r-\theta g^{c}-\theta g^{c} r+\frac{1}{2} \theta(\theta+1)\left(g^{c}\right)^{2} .
$$

With this result, and using (12.52), we can approximate (12.64) as

$$
\rho \cong E\left(r^{i}\right)-\theta E\left(g^{c}\right)-\theta\left\{E\left(r^{i}\right) E\left(g^{c}\right)+\operatorname{cov}\left(r^{i}, g^{c}\right)\right\}+\frac{1}{2} \theta(\theta+1)\left\{E\left(g^{c}\right)^{2}+\operatorname{var}\left(g^{c}\right)\right\},
$$

where we can drop the quadratic terms $\left(E\left(r^{i}\right) E\left(g^{c}\right)\right.$ and $\left.E\left(g^{c}\right)^{2}\right)$ as these may be exceedingly small. This simplifies again to

$$
\rho \cong E\left(r^{i}\right)-\theta E\left(g^{c}\right)-\theta \operatorname{cov}\left(r^{i}, g^{c}\right)+\frac{1}{2} \theta(\theta+1) \operatorname{var}\left(g^{c}\right) .
$$

For a risk free asset, for which $\operatorname{cov}\left(r^{i}, g^{c}\right)=0$, the equation becomes

$$
\bar{r}=\rho+\theta E\left(g^{c}\right)-\frac{1}{2} \theta(\theta+1) \operatorname{var}\left(g^{c}\right),
$$

which again shows the result that the higher the growth rate, the higher the risk free rate, and that the bigger the volatility of consumption the lower the risk free rate! Using (12.69) in (12.68) we obtain

$$
E\left(r^{i}\right)-\bar{r}=\theta \operatorname{cov}\left(r^{i}, g^{c}\right) .
$$

This is the risk premia for an asset $i$. We will see that this equation is incompatible with the observed spread on equities ( $6 \%$ per year). To see this, notice that from the data we know that $\sigma_{g^{c}}=3.6 \%$, $\sigma_{r^{i}}=16.7 \%$, and $\operatorname{corr}_{r^{i}, g^{c}}=.40$. This implies that

$$
\operatorname{cov}_{r^{i}, g^{c}}=(.40) \cdot(.036) \cdot(.167)=0.0024 .
$$

Now we can plug this into (12.70) to get that the following relation has to hold,

$$
0.06=\theta \cdot 0.0024
$$

and this in turn implies $\theta=25$, which is considered too high and incompatible with standard measures of risk aversion (that are closer to 2). Mehra and Prescott (1985) brought this issue up and kicked off a large influx of literature on potential explanations of the equity premium. In recent years the premium seemed, if anything, to have increased even further. But be careful, the increase in the premia may just reflect the convergence of the prices to their equilibrium without the premia. So we can't really say how it plays out from here on.

\subsection{What next?}

Perfect or not, the idea of consumption smoothing has become pervasive in modern macroeconomics. Many of you may have been taught with an undergraduate textbook using a consumption function $C=a+b Y$, with a so-called marginal propensity to consume from income equal to $b$. Modern macroeconomics, both in the version with and without uncertainty, basically states that this equation does not make much sense. Consumption is not a function of current income, but of intertemporal wealth. The distinction is important because it affects how we think of the response of consumption to shocks or taxes. A permanent tax increase will imply a one to one reduction in consumption with no effect on aggregate spending, while transitory taxes have a more muted effect on consumption. These 
intertemporal differences are indistinguishable in the traditional setup but essential when thinking about policy.

The theory of consumption has a great tradition. The permanent income hypothesis was initially stated by Milton Friedman who thought understanding consumption was essential to modern macroeconomics. Most of his thinking on this issue is summarised in his 1957 book $A$ Theory of the Consumption Function (Friedman (1957), though this text, today, would be only of historical interest. The life cycle hypothesis was presented by Modigliani and Brumberg (1954), again, a historical reference.

Perhaps a better starting point for those interested in consumption and savings is Angus Deaton's (1992) Understanding Consumption.

For those interested in exploring value function estimations you can start easy be reviewing Chiang's (1992) Elements of Dynamic Optimization, before diving into Ljungqvist and Sargent (2018) Recursive Macroeconomic Theory. Miranda and Fackler (2004) Applied Computational Economics and Finance is another useful reference. Eventually, you may want to check out Sargent and Stachurski (2014) Quantitative Economics, which is graciously available online at url:http://lectures. quantecon.org/.

There are also several computer programs available for solving dynamic programming models. The CompEcon toolbox (a MATLAB toolbox accompanying Miranda and Fackler (2004) textbook), and the quant-econ website by Sargent and Stachurski with Python and Julia scripts.

If interested in macrofinance, the obvious reference is Cochrane's Asset Pricing (2009) of which there have been several editions. Sargent and Ljungqvist provide two nice chapters on asset pricing theory and asset pricing empirics that would be a wonderful next step to the issues discussed in this chapter. If you want a historical reference, the original Mehra and Prescott (1985) article is still worth reading.

\section{Notes}

${ }^{1}$ Later on in the chapter we will allow the return $r$ also to be stochastic. If such is the case it should be inside the square brackets. We will come back to this shortly.

${ }^{2}$ You can check easily that this specification has positive marginal utility (or can be so), and negative second derivative of utility relative to consumption.

${ }^{3}$ It might also be because policy, such as federal tax deductibility of mortgage interest (and not of rental payments), encourages excessive home ownership.

${ }^{4}$ We can also appeal to irrationality: people may convince themselves that the company they work for is a can't miss investment. And how often have you heard that paying rent is a waste of money?

\section{References}

Beshears, J., Choi, J. J., Laibson, D., \& Madrian, B. (2006). Early decisions: A regulatory framework. National Bureau of Economic Research.

Caballero, R. J. (1990). Consumption puzzles and precautionary savings. Journal of Monetary Economics, 25(1), 113-136.

Friedman, M. (1957). A theory of the consumption function. Princeton University Press.

Ganong, P. \& Noel, P. (2019). Consumer spending during unemployment: Positive and normative implications. American Economic Review, 109(7), 2383-2424. 
Gourinchas, P.-O. \& Parker, J. A. (2002). Consumption over the life cycle. Econometrica, 70(1), 47-89. Hall, R. E. (1978). Stochastic implications of the life cycle-permanent income hypothesis: Theory and evidence. Journal of Political Economy, 86(6), 971-987.

Jorion, P. \& Goetzmann, W. N. (1999). Global stock markets in the twentieth century. The Journal of Finance, 54(3), 953-980.

Kaplan, G., Violante, G. L., \& Weidner, J. (2014). The wealthy hand-to-mouth. National Bureau of Economic Research. https://www.nber.org/system/files/working_papers/w20073/w20073.pdf.

Ljungqvist, L. \& Sargent, T. J. (2018). Recursive macroeconomic theory. MIT Press.

Lucas Jr, R. E. (1978). Asset prices in an exchange economy. Econometrica, 1429-1445.

Mehra, R. \& Prescott, E. C. (1985). The equity premium: A puzzle. Journal of Monetary Economics, 15(2), 145-161.

Miranda, M. J. \& Fackler, P. L. (2004). Applied computational economics and finance. MIT Press.

Modigliani, F. \& Brumberg, R. (1954). Utility analysis and the consumption function: An interpretation of cross-section data. Post Keynesian Economics. Rutgers University Press, 388-436.

Sargent, T. \& Stachurski, J. (2014). Quantitative economics. http://lectures.quantecon.org/.

Shea, J. (1995). Myopia, liquidity constraints, and aggregate consumption: A simple test. Journal of Money, Credit and Banking, 27(3), 798-805. 


\section{Investment}

Investment is one of the most important macroeconomic aggregates, for both short-run and long-run reasons. In the short run, it turns out to be much more volatile than other components of aggregate demand, so it plays a disproportionate role in business cycles. In the long run, investment is capital accumulation, which we have seen is one of the main determinants of output and output growth. That is why we now turn to an inquiry into the determinants of investment.

We have often considered the problem of a firm in partial equilibrium, and analysed how it chooses its optimal level of capital. The firm owns or rents capital, and it can borrow and lend at a fixed interest rate. We saw over and over again that the optimal level of the capital stock for such a firm implies that the marginal product of capital (MPK) equals that interest rate. Investment will thus be whatever is needed to adjust the capital stock to that desired level.

But is that all there is to investment? There are many other issues: the fact that investments are often irreversible or very costly to reverse (e.g. once you decide to build a new plant, it is costly to get rid of it), and that there are costs of installing and operating new equipment. Because of such things, a firm will have a much harder problem than simply immediately increasing its capital stock in response to a fall in the interest rate.

We will now deal with some of these issues, and see how they affect some of the conclusions we had reached in different contexts. We will start by looking at standard practice in corporations and assess the role of uncertainty. We will then put aside the role of uncertainty to develop the Tobin's $\mathrm{q}$ theory of investment.

\subsection{Net present value and the WACC}

The weighted average cost of capital (WACC) is defined as a weighted average of the firm's cost of financing through equity and debt. If a project yields a return higher than the WACC, it is more likely to be implemented.

The best place to start our understanding of investment is to go where all corporate finance books start: investment is decided on the basis of the net present value (NPV) of a project. If a project is started in period 0 and generates a (positive or negative) cash flow of $W_{t}$ in any period $t$ up until time $T$, the NPV will be given by:

\section{How to cite this book chapter:}

Campante, F., Sturzenegger, F. and Velasco, A. 2021. Advanced Macroeconomics: An Easy Guide.

Ch. 13. 'Investment', pp. 189-202. London: LSE Press. DOI: https://doi.org/10.31389/lsepress.ame.m License: CC-BY-NC 4.0. 


$$
N P V=\sum_{t=0}^{T} \frac{1}{(1+r)^{t}} W_{t},
$$

where $r$ is the cost of capital. Typically, one would expect to have a negative cash flow initially, as investment is undertaken, before it eventually turns positive.

The key question is whether this NPV is positive or not. If NPV $>0$, then you should invest; if $\mathrm{NPV}<0$, then you shouldn't. This sounds simple enough, but this immediately begs the question of what interest rate should be used, particularly considering that firms use a complex mix of financing alternatives, including both equity and debt to finance their capital expenditure (CAPEX) programs. In short, what is the cost of capital for a firm? A very popular measure of the cost of capital is the so-called weighted average cost of capital (WACC), which is defined as

$$
\begin{gathered}
\text { WACC }=\alpha_{e q} r_{e q}+\left(1-\alpha_{e q}\right) r_{d e b t}, \\
\alpha_{e q}=\left(\frac{\text { Net worth }}{\text { Total Assets }}\right) .
\end{gathered}
$$

Here, $r_{e q}$ is the return on equity (think dividends) and $r_{\text {debt }}$ is the return on debt issued (think interest). This is a very popular model in part because it is easy to compute. Basically, it allocates the cost of equity using as weight the fraction of your assets that the firm finances with equity. The return on equity can, in turn, be easily derived, say from a CAPM regression, as explained in the previous chapter. With a weight equal to the share of assets that you finance with debt, the formula uses the cost of debt. For this, you may just take the interest cost of the company's issued debt.

In practice, typically firms go through a planning cycle in which the CFO sets a WACC for the following planning cycle and units decide on those projects that have a return higher than that WACC. Only those that have a return higher than the cost of capital get the green light to go ahead. There are several issues with this procedure. Units tend to exaggerate the benefits of their projects to obtain additional resources, projects take a lot of time, and there are many tax-induced distortions (such as reporting investments as expenses to get a tax credit). A lot of corporate finance is devoted to exploring these and other issues.

\subsection{1 | Pindyck's option value critique}

Investment is irreversible, so there is a significant option value when investing. This section illustrates how the value to wait can be essential in evaluating the attractiveness of investment projects.

Investment is a decision in which the presence of uncertainty makes a critical difference. This is because investment is mostly irreversible. It follows that there are option-like features to the investment decision that are extremely relevant. Consider, for example, a project with an NPV of zero. Would you pay more than zero for it? Most probably yes, if the return of the project is stochastic and you have the possibility of activating the project in good scenarios. In other words, a zero NPV project has positive value if it gives you the option to call it when, and only when, it makes you money. In that sense, it is just like a call option - i.e. one in which you purchase the right to buy an asset at some later date at a given price. People are willing to pay for a call option. This line of reasoning is critical, for 
example, in the analysis of mining rights and oil fields. Today an oil field may not be profitable, but it sure is worth more than zero if it can be tapped when energy prices go up. ${ }^{1}$

One of the most studied implications of this option-like feature is when there is an option value to waiting. This is best described by an example such as the following. Suppose you can make an initial investment of $\$ 2200$, and that gives you the following stochastic payoff:

$$
\begin{array}{cccc}
\begin{array}{c}
t=0 \\
\end{array} & & t=1 & t=2 \\
P_{0}=200 & P_{1}=300 & \ldots \\
& & & \\
& 1-q & P_{1}=100 & \ldots
\end{array}
$$

That is, in the first period you make $\$ 200$ for sure, but from then onward the payoff will be affected by a shock. If the good realisation of the shock occurs (and let's assume this happens with probability $q$ ), you get $\$ 300$ forever. If you are unlucky, you get $\$ 100$ forever instead. Suppose $q=0.5$ and $r=0.10$. Given this information, the expected NPV of the project, if it is considered at $t=0$, is

$$
N P V=-2200+\sum_{t=0}^{\infty} \frac{200}{(1.1)^{t}}=-2200+2200=\$ 0 .
$$

In other words, this is a really marginal investment opportunity. But now consider the option of waiting one period, so that the uncertainty gets resolved, and the project only happens if the good state gets realised (which happens with a $50 \%$ probability). Then we have

$$
N P V=0.5\left[-\frac{2200}{1.1}+\sum_{t=1}^{\infty} \frac{300}{(1.1)^{t}}\right]=0.5\left[-\frac{2200}{1.1}+\frac{300}{(1.1)}\left(\frac{1}{1-\frac{1}{1.1}}\right)\right]=500 !
$$

As can readily be seen this is a much better strategy. What was missing in (13.4) was the option value (of $\$ 500$ ) that the entrepreneur was foregoing by implementing the project in period 0 . In other words, she should be willing to pay a substantial amount for the option of waiting until period 1.

This option value argument explains why a firm does not shut down in the first month it loses money - staying open has the value of keeping alive the potential for rewards when things get better. It also explains why people don't divorce whenever marriage hits its first crisis, nor do they quit their job when they have a bad month. These are all decisions that are irreversible (or at least very costly to reverse), and that have uncertain payoffs over time. In sum, they are very much like investment decisions!

A critical lesson from considering the option value entailed by irreversible (or costly reversible) decisions is that uncertainty increases the option value. If there is a lot of variance, then even though the business may be terrible right now, it makes sense to wait instead of shutting down because there is a chance that things could be very good tomorrow. This means that lots of uncertainty will tend to depress the incentive to make investments that are costly to reverse. A firm will want to wait and see instead of committing to building an extra plant; a farmer will want to wait and see before buying that extra plough, and so on. This idea underlies those claims that uncertainty is bad for investment. ${ }^{2}$ 


\section{2 | The adjustment cost model}

Why don't firms move directly to their optimal capital stock? Time to build or adjustment costs prevent such big jumps in capital and produce a smoother investment profile more akin to that observed in the data. This section introduces adjustment costs to capital accumulation delivering a smoother demand for investment.

Let us now go back to our basic framework of intertemporal optimisation, but introducing the crucial assumption that the firm faces adjustment costs of installing new capital. For any investment that the firm wants to make, it needs to pay a cost that varies with the size of that investment. That is to say, the firm cannot purchase whatever number of new machines it may desire and immediately start producing with them; there are costs to installing the new machines, learning how to operate them, etc. The more machines it buys, the greater the costs. ${ }^{3}$

If that is the case, how much capital should the firm install, and when? In other words, what is optimal investment?

\subsection{1 | Firm's problem}

The firm's objective function is to maximise the discounted value of profits:

$$
\int_{0}^{\infty} \pi_{t} e^{-r t} d t
$$

where $\pi_{t}$ denotes firm profits and $r>0$ is (constant and exogenously-given) real interest rate. The profit function is ${ }^{4}$

$$
\pi_{t}=y_{t}-\psi\left(i_{t}, k_{t}\right)-i_{t},
$$

where $y_{t}$ is output and $\psi\left(i_{t}, k_{t}\right)$ is the cost of investing at the rate $i_{t}$, when the stock of capital is $k_{t}$. The term $\psi\left(i_{t}, k_{t}\right)$ is the key to this model; it implies adjustment costs, or costs of investing. Notice that if there are no costs of adjustment, given our assumption of a constant and exogenous interest rate, firms should go right away to their optimal stock. This would give an instantaneous investment function that is undefined, the investment rate either being zero or plus or minus infinite. However, in reality it seems that investment decisions are smoother and this has to mean that there are costs that make it very difficult if not impossible to execute large and instantaneous jumps in the stock of capital. Why would there be costs? We can think of several reasons. One is time-to-build; it simply takes time to build a facility, a dam, a power plant, a deposit, etc. This naturally smooths investment over time. Now, if you really want to hurry up, you can add double shifts, more teams, squeeze deadlines, etc., but all this increases the cost of investment expansions. We thus introduce the costs of adjustment equation as a metaphor for all these frictions in the investment process.

What is the equation of motion that constrains our firm? It is simply that the growth of capital must be equal to the rate of investment:

$$
\dot{k}_{t}=i_{t}
$$

The production function is our familiar

$$
y_{t}=A f\left(k_{t}\right),
$$

where $A$ is a productivity coefficient and where $f^{\prime}(\cdot)>0, f^{\prime \prime}(\cdot)<0$, and Inada conditions hold. 
Next, specialise the investment cost function to be

$$
\psi\left(i_{t}, k_{t}\right)=\frac{1}{2 \chi} \frac{\left(i_{t}\right)^{2}}{k_{t}},
$$

where $\chi>0$ is a coefficient. Figure 13.1 depicts this function.

Figure 13.1 Adjustment costs

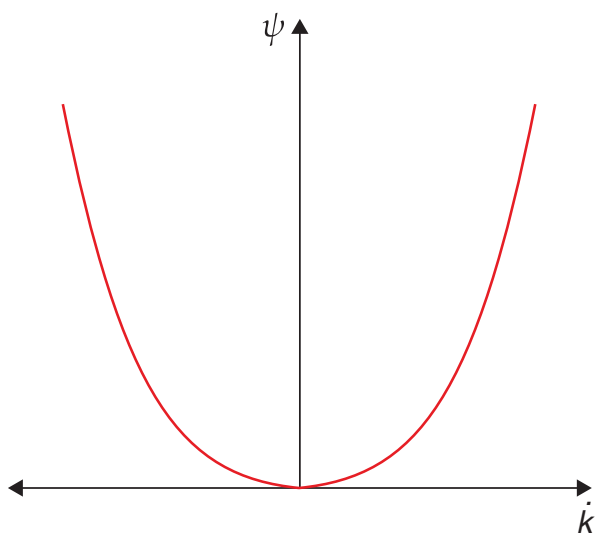

The important assumption is that the costs of adjustment are convex, with a value of zero at $i_{t}=0$. The latter means that there is no fixed cost of adjustment, which is a simplifying assumption, while the former captures the idea that the marginal cost of adjustment rises with the size of that adjustment.

\section{Solving this problem}

The Hamiltonian can be written as

$$
H=A f\left(k_{t}\right)-\frac{1}{2 \chi} \frac{\left(i_{t}\right)^{2}}{k_{t}}-i_{t}+q_{t} i_{t},
$$

where $q_{t}$ is the costate corresponding to the state $k_{t}$, and the control variable is $i_{t}$. The first order condition with respect to the control variable is

$$
\frac{\partial H}{\partial i_{t}}=0 \Rightarrow \frac{1}{\chi} \frac{i_{t}}{k_{t}}=q_{t}-1
$$

The law of motion for the costate is

$$
\dot{q}_{t}=q_{t} r-\frac{\partial H}{\partial k_{t}}=q_{t} r-A f^{\prime}\left(k_{t}\right)-\frac{1}{2 \chi}\left(\frac{i_{t}}{k_{t}}\right)^{2} .
$$

The transversality condition is

$$
\lim _{T \rightarrow \infty}\left(q_{T} k_{T} e^{-r T}\right)=0
$$




\subsection{2 | Tobin's q}

Our model of investment delivers the result that investment is positive if the value of capital is larger than the replacement cost of capital. This is dubbed Tobin's q theory of investment in honour of James Tobin, who initially proposed it.

Recall that the costate $q_{t}$ can be interpreted as the marginal value (shadow price) of the state $k_{t}$. In other words, it is the value of adding an extra unit of capital. What does this price depend on?

Solving (13.13) forward yields

$$
q_{T}=q_{t} e^{r(T-t)}-\int_{t}^{T}\left[A f^{\prime}\left(k_{v}\right)+\frac{1}{2 \chi}\left(\frac{i_{v}}{k_{v}}\right)^{2}\right] e^{r(T-v)} d v .
$$

Dividing this by $e^{r T}$ and multiplying by $k_{T}$ yields

$$
k_{T} q_{T} e^{-r T}=k_{T}\left\{q_{t} e^{-r t}-\int_{t}^{T}\left[A f^{\prime}\left(k_{v}\right)+\frac{1}{2 \chi}\left(\frac{i_{v}}{k_{v}}\right)^{2}\right] e^{-r v} d v\right\} .
$$

Next, applying the TVC condition (13.14), we have

$$
\lim _{T \rightarrow \infty}\left\{k_{T}\left(q_{t} e^{-r t}-\int_{t}^{T}\left[A f^{\prime}\left(k_{v}\right)+\frac{1}{2 \chi}\left(\frac{i_{v}}{k_{v}}\right)^{2}\right] e^{-r v} d v\right)\right\}=0 .
$$

If $\lim _{T \rightarrow \infty} k_{T} \neq 0$ (it will not be - see below), this last equation implies

$$
q_{t} e^{-r t}-\int_{t}^{\infty}\left[A f^{\prime}\left(k_{v}\right)+\frac{1}{2 \chi}\left(\frac{i_{v}}{k_{v}}\right)^{2}\right] e^{-r v} d v=0,
$$

or

$$
q_{t}=\int_{t}^{\infty}\left[A f^{\prime}\left(k_{v}\right)+\frac{1}{2 \chi}\left(\frac{i_{v}}{k_{v}}\right)^{2}\right] e^{-r(v-t)} d v .
$$

Hence, the price of capital is equal to the present discounted value of the marginal benefits of capital, where these have two components: the usual marginal product $\left(A f^{\prime}\left(k_{t}\right)\right)$ and the marginal reductions in investment costs that come from having a higher capital stock in the future.

The fact that $q$ is the shadow value of an addition in the capital stock yields a very intuitive interpretation for the nature of the firm's investment problem. A unit increase in the firm's capital stock increases the present value of the firm's profits by $q$, and this raises the value of the firm by $q$. Thus, $q$ is the market value of a unit of capital.

Since we have assumed that the purchase price of a unit of capital is fixed at $1, q$ is also the ratio of the market value of a unit of capital to its replacement cost. Tobin (1969) was the first to define this variable, nowadays known as Tobin's q.

Notice that (13.12) says that a firm increases its capital stock if the market value of the capital stock exceeds the cost of acquiring it, and vice versa. This is known as Tobin's $q$-theory of investment. 


\subsubsection{The dynamics of investment}

Rearranging (13.12) and using (13.8), we can obtain

$$
\dot{k}_{t}=\chi\left(q_{t}-1\right) k_{t} .
$$

Next, using (13.20) in (13.13) we have

$$
\dot{q}_{t}=r q_{t}-A f^{\prime}\left(k_{t}\right)-\frac{1}{2} \chi\left(q_{t}-1\right)^{2} .
$$

Notice that (13.20) and (13.21) are a system in two differential equations in two unknowns, which can be solved independently of the other equations in the system. What is the interpretation of this system? Taking only a minor liberty, we can refer to this as a system in the capital stock and the price of capital.

\section{Initial steady state}

Return to the system given by equations (13.20) and (13.21). It is easy to show that, in a steady state (i.e. a situation where growth rates are constant), it must be the case that these growth rates must be zero. ${ }^{5}$ Let ${ }^{*}$ denote steady state variables. From (13.20), $\dot{k}_{t}=0$ implies $q^{*}=1$. In turn, setting $\dot{q}_{t}=0$ in (13.21) implies $r=A f^{\prime}\left(k^{*}\right)$, which shows that the marginal product of capital is set equal to the rate of interest. (Have we seen that before?) It follows that, in steady state, firm output is given by $y^{*}=A f\left(k^{*}\right)$. Note that this is true only in steady state, unlike what we had in previous models, where this was the optimality condition everywhere!

\section{Dynamics}

The system (13.20) and (13.21) can be written in matrix form as

$$
\left[\begin{array}{c}
\dot{k}_{t} \\
\dot{q}_{t}
\end{array}\right]=\Omega\left[\begin{array}{c}
k_{t}-k^{*} \\
q_{t}-q^{*}
\end{array}\right],
$$

where

$$
\Omega=\left[\begin{array}{ll}
\left.\frac{\partial \dot{k}}{\partial k}\right|_{S S} & \left.\frac{\partial \dot{k}}{\partial q}\right|_{S S} \\
\left.\frac{\partial \dot{q}}{\partial k}\right|_{S S} & \left.\frac{\partial \dot{q}}{\partial q}\right|_{S S}
\end{array}\right] .
$$

Note that

$$
\begin{gathered}
\left.\frac{\partial \dot{k}}{\partial k}\right|_{S S}=0 \\
\left.\frac{\partial \dot{k}}{\partial q}\right|_{S S}=\chi k^{*} \\
\left.\frac{\partial \dot{q}}{\partial k}\right|_{S S}=-A f^{\prime \prime}\left(k^{*}\right)
\end{gathered}
$$




$$
\left.\frac{\partial \dot{q}}{\partial q}\right|_{S S}=r
$$

so that

$$
\Omega=\left[\begin{array}{ll}
0 & \chi k^{*} \\
-A f^{\prime \prime}\left(k^{*}\right) & r
\end{array}\right] .
$$

This means that

$$
\operatorname{Det}(\Omega)=A f^{\prime \prime}\left(k^{*}\right) \chi k^{*}<0 .
$$

We know that $\operatorname{Det}(\Omega)$ is the product of the roots of the matrix $\Omega$. If this product is negative, the roots must have different signs. Note that $q_{t}$ is a jumpy variable, and $k_{t}$ is a sticky variable. With one positive root and one negative root, the system is saddle-path stable. Figure 13.2 shows the corresponding phase diagram.

Suppose starting at the steady state, the productivity parameter $A$ falls to a lower permanent level $A^{\prime}<A$. Let us focus on the evolution of the capital stock $k_{t}$ and its price $q_{t}$, shown in Figure 13.3. The drop in $A$ shifts the $\dot{q}=0$ schedule to the left. The other locus is unaffected. The steady state of the economy also moves left. The new steady state capital stock is $k^{* \prime}<k^{*}$.

Dynamic adjustment is as follows. $q$ falls on impact all the way to the saddle path that goes through the new steady state. Over time the system moves along the new saddle path until it reaches the new steady state. Along this trajectory the rate of investment is negative, eventually hitting $\dot{k}_{t}=0$ as the economy lands on the new steady state. Notice that during the transition path the price of the asset increases. Why would it increase if the productivity of capital has fallen? Remember that at all times the asset has to deliver the opportunity cost of capital ( $r$ ), if it does not you should sell the asset (this is the reason it's price falls). While the economy adjusts to its lower capital stock, the marginal product of capital is lower. Thus, you should expect a capital gain if you are to hold the asset. The price initially drops sufficiently to generate that capital gain.

Figure 13.2 The dynamics of investment

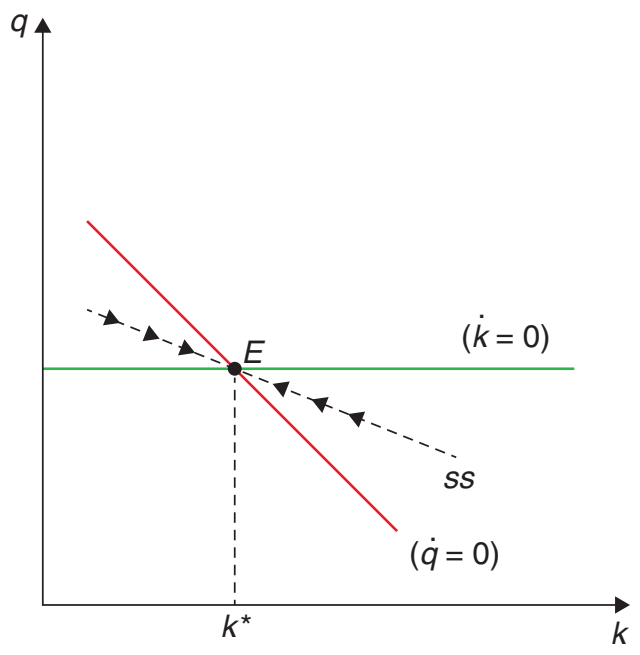


Figure 13.3 The adjustment of investment

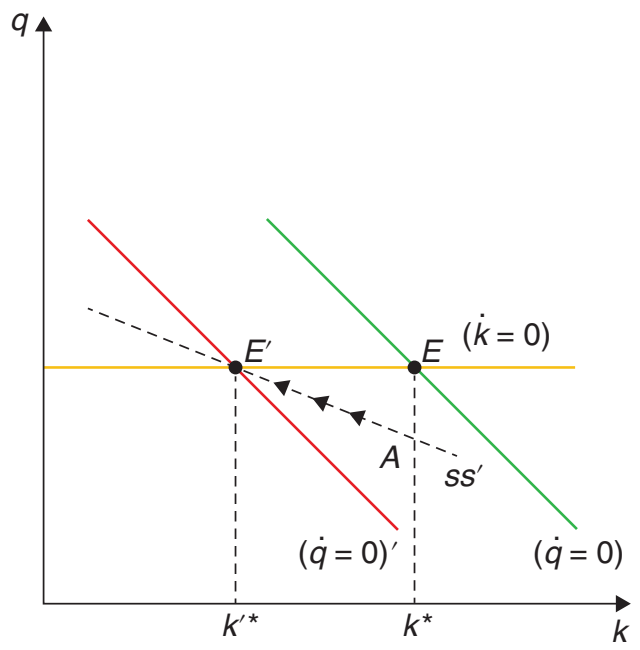

\subsubsection{The role of $\chi$}

We can see from the equations for the steady state that the parameter that indicates the costliness of adjustment does not matter for $k^{*}$ or $y^{*}$. But it does matter for the dynamics of adjustment.

Note that as $\chi$ falls, costs of investment rise, and vice versa. In the limit, as $\chi$ goes to zero, capital never changes; we see from (13.20) that, in this, case $\dot{k}_{t}=0$ always.

Consider what would happen to the reaction of capital and its price to the previous shock as $\chi$ rises. One can show (solving the model explicitly) that the higher $\chi$, the lower the cost of adjustment and the flatter the saddle path. Intuitively, since with high $\chi$ adjustment will be fairly cheap and, therefore, speedy, the price of capital $q$ does not have to jump by a lot to clear the market.

In the limit, as $\chi$ goes to infinity, adjustment is costless and instantaneous. The capital stock is no longer a sticky variable, and becomes a jumpy variable. Therefore, its price is always 1 , and the system moves horizontally (along $\dot{k}=0$ ) in response to any shocks that call for a different steady state capital stock.

\subsection{Investment in the open economy}

In a small open economy, introducing a smooth adjustment of investment implies that the current account will change as a result of shocks. A somewhat counterintuitive result is that a negative productivity shock will lead to a surplus in the current account, as capital will fall gradually and consumption anticipates the future decline.

We can now embed the investment behaviour of the firm in a small open economy framework of Chapter 4. In other words, we revisit the open-economy Ramsey model that we have seen before, but now with the more realistic feature of adjustment costs. We want to understand how investment interacts with consumption and savings and how it matters for the trade balance and the current 
account. We will see that the assumption of adjustment costs has important implications, particularly for the latter.

Consider a small open economy perfectly integrated with the rest of the world in both capital and goods markets. There are two assets: the international bond and domestic capital, just as we have seen before.

In the small open economy, there is a representative consumer and a representative firm. The former can invest in international bonds or in shares of the firm. In fact the consumer owns all the shares of the firm, and receives all of its profits.

\subsection{1 | The consumer's problem}

The utility function is

$$
\int_{0}^{\infty} u\left(c_{t}\right) e^{-\rho t} d t
$$

where $c_{t}$ denotes consumption of the only traded good and $\rho(>0)$ is the rate of time preference. We assume no population growth.

The consumer's flow budget constraint is

$$
\dot{b}_{t}=r b_{t}+\pi_{t}-c_{t},
$$

where $b_{t}$ is the (net) stock of the internationally-traded bond; $r$ is the (constant and exogenouslygiven) world real interest rate; and $\pi_{t}$ is firm profits. Notice that the consumer is small and, therefore, takes the whole sequence of profits as given when maximising his utility.

Notice that the LHS of the budget constraint is also the economy's current account: the excess of national income (broadly defined) over national consumption.

Finally, the solvency (No-Ponzi game) condition is

$$
\lim _{T \rightarrow \infty} b_{T} e^{-r T}=0 .
$$

The Hamiltonian can be written as

$$
H=u\left(c_{t}\right)+\lambda_{t}\left[r b_{t}+\pi_{t}-c_{t}\right],
$$

where $\lambda_{t}$ is the costate corresponding to the state $b_{t}$, while control variables is $c_{t}$.

The first order condition with respect to the control variables is

$$
u^{\prime}\left(c_{t}\right)=\lambda_{t}
$$

The law of motion for the costate is

$$
\dot{\lambda}_{t}=\lambda_{t}(\rho-r)=0,
$$

where the second equality comes from the fact that, as usual, we assume $r=\rho$.

Since $\lambda$ cannot jump in response to anticipated events, equations (13.34) and (13.35) together say that the path of consumption will be flat over time. In other words, consumption is perfectly smoothed over time. Along a perfect foresight path the constant value of $c_{t}$ is given by

$$
c_{0}=c_{t}=r b_{0}+r \int_{0}^{\infty} \pi_{t} e^{-r t} d t, \quad t \geq 0 .
$$


Consumption equals permanent income, defined as the annuity value of the present discounted value of available resources.

Notice that the second term on the RHS of (13.36) is the present discounted value of profits, which is exactly the object the firm tries to maximise. Hence, by maximising that, the firm maximises the feasible level of the consumer's consumption, and (indirectly) utility.

\subsection{2 | Bringing in the firm}

We now need to solve for the path of investment and output. But we have done that already, when we solved the problem of the firm. We know that the firm's behaviour can be summarised by the initial condition $k_{0}>0$, plus the pair of differential equations

$$
\dot{k}_{t}=\chi\left(q_{t}-1\right) k_{t} .
$$

and

$$
\dot{q}_{t}=r q_{t}-A f^{\prime}\left(k_{t}\right)-\frac{1}{2} \chi\left(q_{t}-1\right)^{2} .
$$

Recall that (13.37) and (13.38) are a system of two differential equations in two unknowns, which can be solved independently of the other equations in the system.

Recall also that profits are defined as

$$
\pi_{t}=A f\left(k_{t}\right)-\psi\left(\dot{k}_{t}, k_{t}\right)-\dot{k}_{t} .
$$

- Once we have a solution (13.37) and (13.38), we know what $k_{t}, \dot{k}_{t}, q_{t}$ and $\dot{q}_{t}$ are.

- With that information in hand, we can use (13.39) to figure out what the whole path for profits $\pi_{t}$ will be.

- Knowing that, we can use equation (13.36) to solve for consumption levels.

- Knowing output levels $A f\left(k_{t}\right)$, investment rates $\dot{k}_{t}$, and consumption levels $c_{0}$, we can use this information plus the budget constraint (13.31) to figure out what the current account $\dot{b}_{t}$ is and, therefore, the path of bond-holdings $b_{t}$.

\subsection{3 | Initial steady state}

Consider the steady state at which debt holdings are $b_{0}$ and the capital stock is constant. Let stars denote steady state variables. From (13.37), $\dot{k}_{t}=0$ implies $q^{*}=1$. In turn, setting $\dot{q}_{t}=0$ in (13.38) implies $r=A f^{\prime}\left(k^{*}\right)$, which shows that the marginal product of capital is set equal to the world rate of interest. It follows that, in steady state, output is given by $y^{*}=A f\left(k^{*}\right)$. Finally, consumption is given by

$$
c^{*}=r b_{0}+y^{*} .
$$

In the initial steady state, the current account is zero. The trade balance may be positive, zero, or negative depending on the initial level of net foreign assets:

$$
T B \equiv y^{*}-c^{*}=-r b_{0} .
$$




\subsubsection{The surprising effects of productivity shocks}

Suppose again that, starting at this steady state, the productivity parameter $A$ falls to a lower permanent level $A^{\prime}<A$. To make life simpler, suppose that initially bond-holdings are zero $\left(b_{0}=0\right)$.

Focus first on the evolution of the capital stock $k_{t}$ and its price $q_{t}$, shown in Figure 13.3. The drop in $A$ shifts the $\dot{q}=0$ schedule to the left. The other locus is unaffected. The steady state of the economy also moves left. The new steady state capital stock is $k^{* \prime}<k^{*}$.

At time zero, $q$ falls on impact all the way to the saddle path that goes through the new steady state. Over time the system moves along the new saddle path until it reaches the new steady state. Along this trajectory the rate of investment is negative, eventually hitting $\dot{k}_{t}=0$ as the economy lands on the new steady state.

Notice that net output, defined as $y_{t}-\dot{k}_{t}-\psi\left(\dot{k}_{t}, k_{t}\right)$, may either go up or down initially, depending on whether the fall in gross output $y_{t}$ is larger or smaller than the change in costs associated with the decline in investment. Over the long run, however, the effect is unambiguous: Net output is lower, since gross output falls and investment tends to zero. Figure 13.4 shows net output falling initially, and then declining further to its new steady state level.

The level of consumption is constant and given by

$$
c_{0}^{\prime}=r \int_{0}^{\infty}\left(A^{\prime} f\left(k_{t}\right)-\dot{k}_{t}-\psi\left(\dot{k}_{t}, k_{t}\right)\right) e^{-r t} d t<c_{0} \quad t \geq 0 .
$$

Graphically (in terms of Figure 13.4), consumption is determined by the condition that the thatched areas above and below it be equal in present value.

What about the current account? Since initial bonds are zero, having consumption below net output (see Figure 13.4) must imply that the economy is initially running a current account surplus, saving in anticipation of the lower output in the future. In the new steady state, the net foreign asset position of the economy is that of a creditor: $b^{* \prime}>0$ and the current account goes back to zero.

Figure 13.4 The effect on the current account

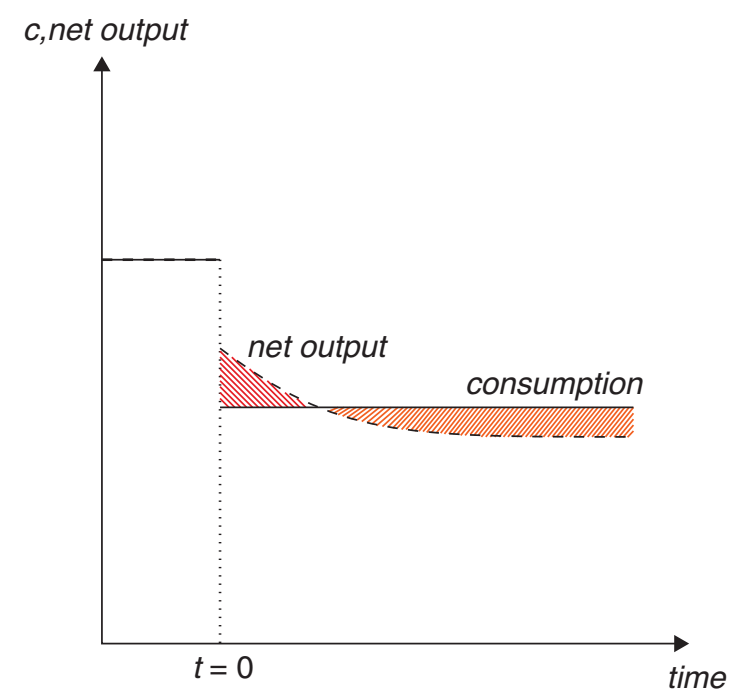


This result led to a novel and surprising interpretation of the current account. Imagine, for example, a fall in productivity that arises from an oil crisis (such as that in the 1970s), affecting an oil importing country. ${ }^{6}$ Figure 13.4 suggests that this shock will lead to a surplus in the current account. Notice that this may challenge your intuition; if oil has become more expensive and this is an oil importing country, shouldn't the current account deteriorate? Why is this wrong? It is wrong because it fails to take into account the adjustment of aggregate spending in response to the shock. The oil shock not only makes imports more expensive, it lowers expected future income. As consumption smooths future decreases in income, it reacts strongly in the short run, in fact, ahead of the output decrease, leading to a surplus. By the same token, if you are an oil-exporting country, a positive shock to the price of oil would stimulate consumption and investment. As output will increase over time the reaction of consumption can be strong, leading to a deficit. Of course this result depends on a number or assumptions, for example that the shock be permanent and believed to be so. Changing any of these assumptions can change this result.

The bottom line is that these intuitions that are aided by our use of a general equilibrium format. In fact, when Sachs et al. (1981) tested these results by looking at the response of the current account to the oil shocks of the 1970's they found that the results of the theory held surprisingly well in the data. Oil exporting countries quickly (though not instantaneously) were experiencing deficits, while oil importing countries managed to show surpluses.

On a final note, you may recall that the adjustment process is quite different from what we had in the open-economy Ramsey model without adjustment costs in response to a permanent shock. There the current account of an economy in which $r=\rho$ was always zero. This was because all adjustments could be done instantaneously - if the shock led the economy to reduce its stock of capital, it could do so immediately by lending abroad. Now, because of adjustment costs, this process takes place over time, and we have current account dynamics in the transition.

\section{4 | What next?}

If you are interested in understanding better the investment process, a good starting point is, again, the Dixit and Pindyck (1994) masterpiece Investment under Uncertainty. The Bloom et al. (2007) paper provides a wonderful reference list with the most important pieces written to that date. In more recent years a debate has ensued on the nature of investment in an increasingly digitalised world where firms do not need so much capital as they do human capital. Crouzet and Eberly (2019) is a good entry point into this debate.

\section{Notes}

${ }^{1}$ The classical reference on this issue is Dixit and Pindyck (1994). See, for example, Brennan and Schwartz (1985) for mining projects. More recently, Schwartz has found that new reserves additions to oil companies reduce the value of the companies. In this case, they are an option to a loss! (See Atanasova and Schwartz (2019)).

2 This issue has a long pedrigee in economics. For a relatively recent reference, with many references thereof, you may want to check Bloom (2009).

${ }^{3}$ Careful with the use of the machines imagery! It brings to mind right away the role of indivisibilities - you can't purchase 3.36 machines - while we will assume that investment is perfectly divisible. Indivisibilities will bring in other issues that are beyond our present scope. 
${ }^{4}$ We refer rather loosely here to profit, but really the equation depicts the free cash flow that the investment project will generate over it's lifetime.

${ }^{5}$ How can we show that? Note that (13.20) immediately implies that, for $\frac{k}{k}$ to be constant, we must have $q$ constant. Using (13.21) to obtain $\frac{\dot{q}}{q}$, and using the fact that $q$ is constant, we see that we must have the ratio $\frac{f^{\prime}(k)}{q}$ constant, which requires that $k$ is also constant.

${ }^{6}$ One way to think about this is by thinking of oil as an input that has become more costly, akin to a fall in labour or capital productivity.

\section{References}

Atanasova, C. \& Schwartz, E. S. (2019). Stranded fossil fuel reserves and firm value. National Bureau of Economic Research.

Bloom, N. (2009). The impact of uncertainty shocks. Econometrica, 77(3), 623-685.

Bloom, N., Bond, S., \& Van Reenen, J. (2007). Uncertainty and investment dynamics. The Review of Economic Studies, 74(2), 391-415.

Brennan, M. J. \& Schwartz, E. S. (1985). Evaluating natural resource investments. Journal of Business, 135-157.

Crouzet, N. \& Eberly, J. C. (2019). Understanding weak capital investment: The role of market concentration and intangibles. National Bureau of Economic Research.

Dixit, A. \& Pindyck, R. S. (1994). Investment under uncertainty. Princeton University Press.

Sachs, J. D., Cooper, R. N., \& Fischer, S. (1981). The current account and macroeconomic adjustment in the 1970s. Brookings Papers on Economic Activity, 1981(1), 201-282.

Tobin, J. (1969). A general equilibrium approach to monetary theory. Journal of Money, Credit and Banking, 1(1), 15-29. 